\title{
Currency Design in the United States and Abroad: Counterfeit Deterrence and Visual Accessibility
}

\author{
Marcela M. Williams and Richard G. Anderson
}

\begin{abstract}
Despite the increasing use of electronic payments, currency retains an important role in the payment system of every country. In this article, the authors compare and contrast trade-offs among currency design features, including those primarily intended to deter counterfeiting and those to improve usability by the visually impaired. The authors conclude that periodic changes in the design of currency are an important aspect of counterfeit deterrence and that currency designers worldwide generally have been successful in efforts to deter counterfeiting. At the same time, currency designers have sought to be sensitive to the needs of the visually impaired. Although trade-offs among goals sometimes have forced compromises, new technologies promise banknotes that are both more difficult to counterfeit and more accessible to the visually impaired. Among the world's currencies, U.S. banknotes are the notes most widely used outside their country of issue and thus require special consideration. (JEL E42, E51)
\end{abstract}

Federal Reserve Bank of St. Louis Review, September/October 2007, 89(5), pp. 371-414.

An efficient and sustainable payment system development process ought to be built around the current and foreseeable payment needs of the users in the economy, such as consumers, government and financial and nonfinancial businesses. These needs should be weighed against the current economic and technical capabilities of the economy to supply the required payment instruments and services in a cost-effective manner.

Guideline 4, Committee on Payment and Settlement Systems, Bank for International Settlements (2006)

D espite the increasing popularity of electronic payments, currency remains an integral part of all nations' payment systems and the most familiar medium for daily face-to-face payments. In most nations, the bulk of the circulating currency is that issued by that nation's monetary authority; in a few cases, the currency of a foreign nation, such as the United States, is widely used. Regardless of the specific currencies in circulation, each nation's payment system has a large number of participants, including consumers, retail businesses, financial institutions, the central bank or other monetary authority, armored car companies and others who transport currency, and third-party currency processors. Everyone who touches currency in a nation's payment system has a stake in recognizing the authenticity of currency ("authenticating”), readily determining its denomination ("denominating"), and-subject to these constraints-minimizing the cost of its handling.

To sustain public confidence in a circulating currency, banknotes must contain features that the public can use to readily judge their authenticity and determine the notes' denominations.

Marcela M. Williams is a senior research associate and Richard G. Anderson is a vice president and economist at the Federal Reserve Bank of St. Louis. Views expressed herein are solely those of the authors and are not necessarily those of the Federal Reserve Bank of St. Louis, the Board of Governors of the Federal Reserve System, the U.S. Treasury, or the Department of Homeland Security. The authors thank numerous colleagues for comments. They also thank, for their cooperation and assistance, the Reserve Bank of Australia, the Bank of Canada, the Bank of Japan, the Sveriges Riksbank, the European Central Bank, the Monetary Authority of Hong Kong, the Hongkong and Shanghai Banking Corporation Limited, the Monetary Authority of Singapore, the Swiss National Bank, the Bank of England, and the United States Bureau of Engraving and Printing. All currency images used within are the property of the respective currency issuers and are used with permission. Responsibility for errors remains with the authors.

(C) 2007, The Federal Reserve Bank of St. Louis. Articles may be reprinted, reproduced, published, distributed, displayed, and transmitted in their entirety if copyright notice, author name(s), and full citation are included. Abstracts, synopses, and other derivative works may be made only with prior written permission of the Federal Reserve Bank of St. Louis. 
Currency design is driven by these considerations, subject to constraints imposed by the desire to minimize the notes' cost and maximize their ease of handling by third parties. Monetary authorities, quite naturally, prefer banknotes that are relatively inexpensive to produce and, other things equal, have a long life in circulation. These considerations make banknote design a mixture of art, science, and economics. ${ }^{1}$ Generally, monetary authorities worldwide recognize that improved public understanding and awareness of the features of their currency assist them in meeting these goals. Yet, studies of public awareness of currency features suggest that often many members of the public are not aware of even a single security feature in their nation's banknotes. ${ }^{2}$

In this article, we compare and contrast design features in banknotes issued by monetary authorities in a number of countries, including the United States. Our focus is on two primary design issues: counterfeit deterrence and high visual accessibility (for both the normal-sighted and visually impaired). ${ }^{3}$ We discuss both those fea-

1 For the economist reading this article, we note that the "currency design problem" may be framed as a constrained optimization problem in which the objective is to maximize the contribution of circulating currency to social welfare. Absent constraints (both economic and technical), social welfare is maximized by producing banknotes that contain "all" desirable features, including those that deter illegal reproduction, make denomination rapid and accurate, make the currency easily used by the blind and visually impaired, and (as with machine-readable features) minimize the cost of high-volume currency handling by third-parties. Because it is reasonable to believe that the objective functions of monetary authorities differ (for example, some might have a relatively larger fraction of their banknotes in circulation abroad, or might have a relatively more highly educated population, or might face relatively higher labor costs for currency handling), the solutions to their optimization problems - the resulting currency designs-will differ The underlying structure of our article is such an "optimization subject to constraints" framework. In our opinion, such formalism contributes little to the public's understanding of currency design issues and, hence, for accessibility to the general reader we avoid the use of such jargon in the article. Interested readers should examine Tables 1 and 2, in which the column headings approximately correspond to the constraints that would appear in a formal KuhnTucker optimization statement of the currency design problem.

2

Published studies on this topic are relatively difficult to locate. An interesting paper is de Heij, DiNunzio, and Strube (2003), which, for the United States, summarizes surveys of public awareness conducted by Deloitte \& Touche for the U.S. Bureau of Engraving and Printing. For a recent study of the euro, see de Heij (2006).

3 Throughout this manuscript, we use the term "visually impaired" to refer to persons with limited visual capacity that affects their ability to carry on their daily lives, and "normal-sighted" to tures that are readily visible to consumers and businesses, and machine-readable features not accessible without machine assistance. Our emphasis is on design features that the public might use to determine the authenticity and denomination of a banknote. In this respect, our views coincide with those expressed by currency experts such as Brian Lang (2002), then head of currency at the Reserve Bank of New Zealand, who emphasized that building sophisticated security features into banknotes is of limited effectiveness if the public is unaware of the features, and that a highly aware public is the best defense against the circulation of counterfeit banknotes. Throughout, our analysis is based on publicly available information regarding currency design considerations and features. To the extent that banknotes contain covert or secret features, these are not discussed here.

U.S. currency is an especially complicated case: Unique in the world, U.S. currency presents special issues because of its widespread usage outside the United States. Although U.S. currency has been held abroad since before the Second World War, outflows accelerated during the 1970s. Recent estimates are that more than 50 percent of all U.S. banknotes in circulation are held outside the United States. ${ }^{4}$ The worldwide presence increases its attractiveness to counterfeiters while, at the same time, councils caution with respect to significant design changes to deter counterfeiting or improve visual accessibility that might confuse the public outside the United States. In foreign nations experiencing political or economic uncertainty, U.S. banknotes are an attractive asset; much of the recent growth in demand for U.S. banknotes has been in countries of the former Soviet Union and Latin America. Indeed, anecdotal press reports tell of Moscow taxi drivers insisting to be paid in U.S. dollars rather than rubles. Other stories tell of merchants in the most

describe those persons who, while perhaps having some diminished vision, are able to conduct daily major life functions, albeit in some cases with an accommodation or limitations. We recognize that these terms are imprecise and that significant disagreement remains regarding the use of such highly descriptive terms. Among other sources, a more complete discussion is available, for example, in National Research Council (1995).

4 U.S. Treasury Department (2006b). 
remote areas of China accepting-and giving change-in U.S. banknotes. The extensive, widespread use of U.S. banknotes benefits American taxpayers because, unlike Treasury bonds, the banknotes are a liability of the U.S. monetary authorities on which no interest is paid. The use of the banknotes also is a social and economic benefit to the residents of foreign countries who might otherwise lack a currency stable in value and widely accepted in transactions. This same popularity also encourages counterfeiting. Counterfeiters range from the casual, who produce a few notes with desktop scanners and ink jet printers or with color copiers, to professionals using sophisticated lithographic printing systems, to foreign governments that print counterfeit "supernotes" on government-owned intaglio presses. ${ }^{5}$ Below, we consider further the ways in which security requirements and a desire for universal acceptability around the world may limit design options for U.S. currency. ${ }^{6}$

We begin by exploring the characteristics of an "ideal" currency and then examine the realworld considerations that affect currency design. We conclude with a comparative analysis of currency features around the world.

\section{WHAT ARE THE CHARACTERISTICS OF AN IDEAL CURRENCY?}

There are relatively few published, analytical studies of currency design. The studies of which we are aware focus on U.S. currency and, for the most part, have been funded by the U.S. Treasury's Bureau of Engraving and Printing (BEP) and conducted by the National Research Council (NRC), including BEP (1983) and NRC (1993, 1995, 2006, 2007). The U.S. Treasury, in collaboration with other government agencies, has published three studies regarding counterfeiting and the demand for U.S. banknotes abroad (U.S. Treasury, 2000, 2003, 2006b). Our analysis necessarily draws heavily on these studies.

\footnotetext{
5 Both the National Research Council (2006) and Mihm (2006) identify North Korea as a producer of "supernotes."

${ }^{6}$ Interested readers should consult U.S. Treasury (2000, 2003, 2006b).
}

The U.S. BEP was established during the U.S. Civil War in an effort to reduce counterfeiting. Since that time, the primary focus of U.S. banknote design has been counterfeit deterrencealthough features that would ease usage by both the visually impaired and normal-sighted users have not been ignored. The NRC's Committee on Next-Generation Currency Design (NRC, 1993) described the features of a "perfect" currency:

- Extremely difficult to duplicate

- Easily recognized by the general public

- Durable (remains visible after considerable wear)

- Can be machine-readable

- Easy to produce at low cost

- Acceptable to the public (aesthetically pleasing)

- Non-toxic and non-hazardous

Table 1 compares and contrasts banknotes' characteristics relative to those of an "ideal currency" for selected countries that belong to the Bank for International Settlements' Committee on Payment Systems and Services. With respect to counterfeit deterrence, the committee argued that no single feature, by itself, can furnish adequate protection against even the casual counterfeiter because nearly all individual features can be simulated by a determined, well-funded counterfeiter. Instead, the committee recommended a "systems approach" that combined several features with aggressive law enforcement and detection efforts.

To introduce ideas and terminology, consider the current U.S. \$50 note (see Figure 1). On the front, the note contains security features including a watermark, color-shifting ink and subtle shades of various colors; on the reverse, the note contains in the lower right corner a visual accessibility feature, the denomination in $14 \mathrm{~mm}$ tall numerals. In the final section of this article, we examine security and visual accessibility features of currencies from several nations.

\section{Accessibility Features}

- Large numeral on reverse

- Large portraits

- Subtle over-printed colors on front 


\section{Figure 1}

\section{U.S. \$50 Note: Security and Accessibility Features}
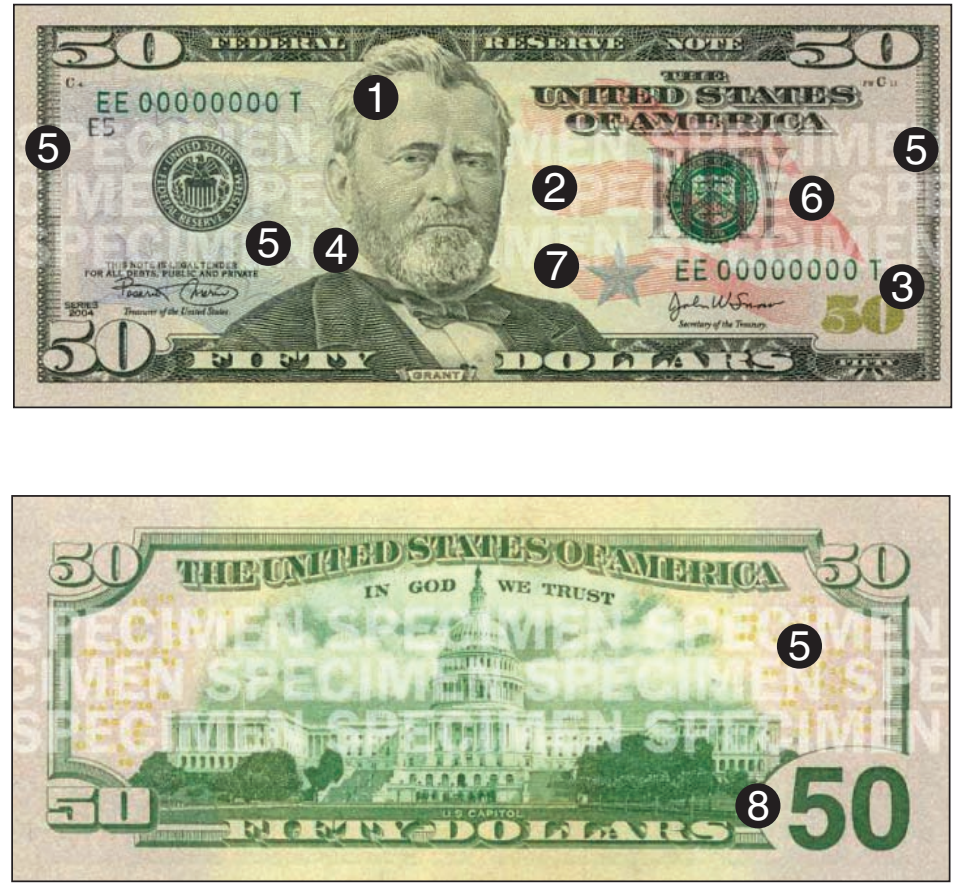

Front

\section{Security Features}

1. Enlarged, off-center portrait

2. Subtle, over-printed colors

3. Color-shifting ink

4. Fine-line printing patterns

5. Microprinting

6. Watermark

7. Security thread

\section{Accessibility Features}

8. Large denomination numeral on reverse

- Enlarged portrait

- Colors that vary by denomination

NOTE: See Tables 1 and 2 and the appendix for a complete listing of security and accessibility features. See also the boxed insert on p. 408 and Figure 11 on p. 409.

SOURCE: U.S. Bureau of Engraving and Printing; www. moneyfactory.com/newmoney.

\section{Security Features}

- Watermark

- Color-shifting inks

- Fine-line printing patterns

- Enlarged off-center portraits

- Machine-readable feature

- Security thread

- Microprinting

Although the task given to the NRC's 1993 committee on currency design was to explore features that deter counterfeiting, the first item on its evaluation criteria was "visual and tactile recognizability," defined as "an assessment of the ease with which a U.S. citizen...could readily recognize the feature in normal ambient illumination unaided, or aided with a simple, inexpensive device." It is widely recognized that the "look and feel" of currency is important for determining whether it is genuine, both for normal-sighted users and the visually impaired. The committee concluded that U.S. currency's unique banknote paper, combined with its raised surface created by intaglio printing, were the essential ingredients for notes to have the correct "feel" of U.S. currency. ${ }^{7}$ More recently, the NRC has issued two detailed technical reports on counterfeit deterrence (NRC,

\footnotetext{
7 Security intaglio printing refers to print produced from handengraved plates with a recessed image. Thick paste inks and high printing pressures are used to create a raised surface on the note that cannot be reproduced by planar printing processes. Virtually all banknotes are printed, at least in part, by intaglio methods. Additional features, such as serial numbers and color, often are added via letterpress or offset printing, although color intaglio is feasible. Van Renesse (2005) and NRC (2006) provide detailed discussions of printing techniques.
} 
2006 and 2007). In broad terms, the findings and recommendations resemble the 1993 report: Currency redesign must be an ongoing process to remain ahead of the improving technology available to counterfeiters.

In 1995, the NRC (via its Committee on Currency Features Usable by the Visually Impaired) issued a report focused solely on visual accessibility (NRC, 1995). This study was commissioned by the BEP, and is, as far as we are aware, the most extensive on the topic. We review its recommendations below. In their scope and completeness, the NRC's 1993 and 1995 studies complement each other. Unfortunately, the studies are almost completely compartmentalized in their suggestions for an ideal currency. The studies omitted comparisons between design features to deter counterfeiting and to increase visual accessibility: The 1993 report (NRC, 1993) considered "ideal" features for counterfeit deterrence, while the 1995 report (NRC, 1995) considered "ideal" visual features. The NRC's 1993 report, for example, in approximately 125 pages, never mentions concerns of the blind or visually impaired. ${ }^{8}$ The NRC's 1995 report, for example, concluded that "features currently used by other countries...can be considered for inclusion in the forthcoming redesign of U.S. currency without compromising the security of American banknotes" (NRC, 1995, p.11). We discuss below features that have been introduced in newer currency designs.

Our analysis of notes issued worldwide suggests that security-related features (including those to deter counterfeiting) and features that enhance visual accessibility often are complementary. For U.S. banknotes, designing currency robust to counterfeiters but also as highly visually accessible as possible perhaps is more challenging due to the widespread use of U.S. dollars abroad; yet, the Treasury's successful education campaign that surrounded introduction of the redesigned $\$ 100$ note suggests that education can overcome initial resistance to design changes. ${ }^{9}$

\footnotetext{
8 The 1993 report is the first report specifically linked to a pending currency redesign. Two previous reports by the NRC are discussed in the 1993 document. One of those earlier reports, in 1985, recommended the security thread and small-size intaglio-printed characters implemented in Series 1990 U.S. banknotes.
}

\section{CURRENCY DESIGN FEATURES TO DETER COUNTERFEITING}

Technological innovation in color copying, scanning, and printing is the most important factor propelling increasingly sophisticated currency designs to deter counterfeiting.

Innovation has intensified the race between increasingly sophisticated banknote counterfeiters and banknote designers. In many lines of business, the improving performance and decreasing cost of information technology have reduced "barriers to entry"- - unfortunately, perhaps, the same is true in counterfeiting. The NRC's most recent technical report (NRC, 2007) concludes that this race eventually will be lost for the current generation of paper-based banknotes and explores a wide range of innovative substrates as a replacement for current banknote paper. The report's overall conclusion echoes the conclusions of previous NRC reports (NRC, 1993, 2006) that only continuous design innovation can sustain a low frequency of counterfeit notes in circulation. The report's engineering analysis of alternative substrates is fascinating but speculative. We leave details of the report to the interested reader and focus herein on current banknote designs and features.

Banknote designers worldwide have introduced a number of features to deter counterfeiting. Features to assist authentication for selected countries are summarized in the first column of Table 1. Such features include novel substrates such as polymer with clear windows that include embossed and printed security features ${ }^{10}$; embedded security threads, including ones that glow different colors under ultraviolet (UV) light ${ }^{11}$; high-relief raised intaglio printing; extra color

\footnotetext{
9 See U.S. Treasury (2000, 2003, and 2006b) for discussions of uncertainty generated abroad by design changes and the accompanying education campaigns. Lambert and Stanton (2001) discuss holdings of U.S. notes abroad relative to the Series 1996 and 2004 design changes.

10 The Reserve Bank of Australia issued the world's first polymer note series between 1992 and 1996. The NRC $(2006,2007)$ reviews the engineering details of such plastics and provides a list of the numerous countries now using such currency.

${ }^{11}$ Among others, U.S. banknotes now contain such threads.
} 
Table 1

Currency Features for Selected Countries, As Reported by the Currency Issuers

\section{Features to assist authentication and denomination (anti-counterfeiting measures)}

Australia

\section{Clear window}

Made of polymer substrate instead of paper

See-through registration device Shadow image Intaglio printing

Background print (offset) Microprinting

Fluorescent ink properties
Features to assist the visually impaired (visual features)

Different sizes

Different colors Intaglio printing

Large numerals

\begin{tabular}{|c|c|}
\hline Canada & $\begin{array}{c}\text { Holographic stripe } \\
\text { Watermark portrait } \\
\text { Windowed color-shifting thread } \\
\text { See-through number } \\
\text { Raised ink/intaglio printing } \\
\text { Fine-line patterns } \\
\text { Microprinting } \\
\text { Fluorescence/UV-light tests } \\
\text { Serial number } \\
\text { Colors }\end{array}$ \\
\hline
\end{tabular}

Euro Currency Area*

"Feel, look and tilt" Made of pure cotton Raised print/intaglio printing

Tactile marks

Watermark

Security thread

See-through number

Perforations

Hologram patch $(€ 50 € 100, € 200, € 500)$

Color-changing number (€50, €100, €200, and €500)

Glossy/iridescent stripe

Microprinting

UV-light tests
Different colors

Tactile symbols

Large high-contrast numerals Machine readable

Hong Kong SAR

Fluorescent machine-readable barcode

Iridescent images

Denomination numeral in optical variable ink

Holographic windowed thread

Concealed image/denomination Intaglio printing

Fluorescent fibers/UV-light tests

Watermarks

Security thread

See-through feature

Serial numbers
Different sizes

Different colors

Large numerals

Intaglio printing

NOTE: *For the 12 member states of the European Monetary Union participating in the single currency. ${ }^{+}$Life span of euro banknotes is calculated by dividing, for each denomination, the average circulation of banknotes during the previous 12 months by the number of banknotes sorted to unfit during the previous 12 months.

SOURCE: European Central Bank. 
Durability

Bank of Australia estimates that polymer notes last at least four times longer than paper notes
Cost of production

Costs are confidential
C\$5: $1-2$ years

$\mathrm{C} \$ 10: 1-2$ years

C\$20: 2-4 years

C\$50: 4-6 years

C\$100: 7-9 years
Approximately CA $\$ 0.09$ per note

$€ 5: 1.2$ years $^{\dagger}$ $€ 0.08$ per banknote

$€ 10: 1.4$ years

$€ 20: 1.5$ years

$€ 50$ : 3.7 years

$€ 100: 8$ years

$€ 200$ : 11.8 years

$€ 500$ : 25.6 years

Approximately 2 years

Costs are confidential 
Table 1, cont'd

\section{Currency Features for Selected Countries, As Reported by the Currency Issuers}

\section{Features to assist authentication and denomination (anti-counterfeiting measures)}

Japan

Singapore

\section{Watermark}

Ultra-fine-line printing

Intaglio printing

Microprinting

Luminescent ink

Hologram

Latent image

Pearl ink
Features to assist the visually impaired (visual features)

Tactile marks/intaglio printing

Different sizes

Different colors

\section{Microprinting \\ Kinegram \\ Lithographic print \\ Engraved portrait \\ Braille codes}

Asymmetrical serial numbers (vertical and horizontal)

Anti-color-copying line structures

Lift twin

Intaglio printing

Highlight watermark

Watermark

Perfect registration

Security thread

Invisible feature: non-reflective under UV light

See-through windows on polymer notes
Sweden

Watermark

Security thread

See-through picture

Intaglio printing

Additional features for banknotes with foil strip:

Fluorescent picture

Microlettering

Foil strip-hologram

Shimmering mother-of-pearl ink

Motion feature

$$
\begin{gathered}
\text { Transparent register } \\
\text { Watermark digits } \\
\text { Intaglio printing (digits) } \\
\text { Perforated number } \\
\text { Optically variable ink } \\
\text { UV digits } \\
\text { Metallic digits } \\
\text { Tilt effect }
\end{gathered}
$$

Braille codes

Different colors

Different sizes

Intaglio printing

NOTE: ${ }^{\ddagger}$ Costs of producing a banknote (conception and design, paper, printing, information) average approximately 30 centimes per new note. Yearly production assuming a 3 -year lifespan is 10 centimes per note in circulation. 


\section{Durability}

$¥ 1,000$ : $1-2$ years

$¥ 5,000$ : $1-2$ years

$¥ 10,000$ : $4-5$ years

\section{Cost of production}

$¥ 15.1$ per banknote
S\$2 polymer: $72-96$ months

(issued in Jan 2006, still monitoring the performance)

S\$5 paper: $18-24$ months

S\$10 paper: $24-36$ months

S\$10 polymer: $72-96$ months

(issued in May 2004, still monitoring the performance)

S\$50 paper: $24-36$ months

S\$100 paper: $48-60$ months

S\$1,000 paper: $48-60$ months

S\$10,000 paper: 48-60 months
S\$2 polymer: $\mathrm{S} \$ 0.10$

$\mathrm{S} \$ 5$ paper: $\mathrm{S} \$ 0.10$

S\$10 paper: $\$ \$ 0.09$

S\$10 polymer: $S \$ 0.12$

$\mathrm{S} \$ 50$ paper $\mathrm{S} \$ 0.08$

S\$100 paper $\$ \$ 0.07$

$S \$ 1,000$ paper $\$ \$ 0.09$

$\mathrm{S} \$ 10,000$ paper $\mathrm{S} \$ 0.55$
Varies by denomination

20 kronor: about 1 year

1,000 kronor: about 5 years
Approximately 7.5 US cents per banknote
10 CHF: 2 years

20 CHF: 1.5 years

50 CHF: 1.5 years

100 CHF: 3.5 years

200 CHF: 3 years

1,000 CHF: 10 years
About CHF 0.30 centimes per note ${ }^{\ddagger}$ 
Table 1, cont'd

Currency Features for Selected Countries, As Reported by the Currency Issuers

\begin{tabular}{|c|c|c|}
\hline & $\begin{array}{l}\text { Features to assist authentication } \\
\text { and denomination } \\
\text { (anti-counterfeiting measures) }\end{array}$ & $\begin{array}{c}\text { Features to assist the visually impaired } \\
\text { (visual features) }\end{array}$ \\
\hline United Kingdom & $\begin{array}{l}\text { Cotton and linen paper } \\
\text { Metallic thread } \\
\text { Watermark } \\
\text { Print quality } \\
\text { Hologram } \\
\text { UV-light tests } \\
\text { Microlettering } \\
\text { Foil (on } £ 50 \text { note) }\end{array}$ & $\begin{array}{c}\text { Different sizes } \\
\text { Large denomination numerals } \\
\text { Densely colored recognition symbols } \\
\text { to indicate denomination: } \\
£ 5 \text { : turquoise circle, } \\
£ 10 \text { : orange diamond, } \\
£ 20 \text { : purple square (on the old } £ 20 \text { note), } \\
£ 50 \text { : red triangle }\end{array}$ \\
\hline United States & $\begin{array}{c}\text { Watermark } \\
\text { Color-shifting inks } \\
\text { Fine-line printing patterns } \\
\text { Enlarged off-center portraits } \\
\text { Low-vision feature } \\
\text { Machine-readable feature } \\
\text { Security thread } \\
\text { Microprinting }\end{array}$ & $\begin{array}{l}\text { Oversize denomination numeral on reverse } \\
\text { Larger portraits (than previous designs) } \\
\text { Subtle over-printed colors on front }\end{array}$ \\
\hline
\end{tabular}

NOTE: SIn the year to end-February 2006, 978 million notes were produced at a total cost of $£ 28$ million. IFigure based on 2001 fiscal year figures: A total of $7,004,800,000$ notes were produced, and $\$ 219,240,000$ was expended on currency production.

features on bills; magnetic ink; and various embedded machine-readable features. ${ }^{12}$ Counterfeit deterrence features are discussed further in the final section of this article.

United States banknotes contain a large number of security features to deter counterfeiting, including embedded security threads that glow different colors by denomination under UV light; large, complex line-drawn presidential portraits; watermarks; embedded fibers; color-shifting ink (the color of which differs by denomination); microprinting too small to be reproduced by current-generation photographic copiers and consumer-level scanners; fine-line printing; color over-printing in subtle shades; and embedded machine-readable features. Machine-readable

\footnotetext{
12 Electronic handheld note readers, of significant value to the visually impaired, perhaps can use machine-readable features-but specific technical designs are proprietary and confidential. Although several currency issuers have informed us that the machine-readable features of their banknotes might be suitable for handheld denominators, to our knowledge such machines are available only for Canadian and U.S. banknotes.
}

features, most of which vary by denomination, include the notes' optical spectrum and image (including color-shifting inks, and a fluorescent strip that glows in denomination-specific colors under certain frequencies of light), magnetic ink, UV spectrum, and infrared ink pattern (NRC, 2006, pp. 12-13). The NRC notes that machinereadable features are useful both to authenticate notes and to determine notes denomination. Single-note denominators such as those installed in retail vending machines, for example, "typically use infrared, broad-wavelength optical, or magnetic sensors to detect denomination-specific features," while single-note authenticators "also detect ultraviolet and fluorescent patterns." (NRC, 2006, p. 12). The report notes that low-quality counterfeit notes most commonly are identified by low optical image quality, lack of magnetic and/or infrared ink, or incorrect paper fluorescence (discussed further below). Detection of high-quality counterfeits may require careful sensing of magnetic, infrared, or UV signatures. 


\section{Durability}

Ranges from around 1 year for the $£ 5$ note, to 5 or more years for the $£ 50$ note
Cost of production

Approximately $£ 0.029$ per banknote p $^{\S}$
\$1: 21 months

\$ 5: 16 months

\$10: 18 months

\$20: 24 months

\$50: 55 months

\$100: 89 months
Approximately 3 cents per banknoteף
Magnetic ink is a difficult feature for counterfeiters to replicate, although careful procedures perhaps can maintain magnetic material in suspension long enough for printing; the NRC report notes that 90 percent of counterfeit notes found by high-speed verifiers are detected as a result of incorrect magnetic signatures (NRC, 2006, p. 12). ${ }^{13}$

The paper substrate of U.S. banknotes has a difficult-to-duplicate light green-yellow tint that is a major deterrent to counterfeiting (NRC, 2006). The paper is manufactured under close security by a single U.S. firm from a mixture of 75 percent cotton and 25 percent flax. ${ }^{14}$ The color is a characteristic of the paper manufacturing process during which no clay or other whitening agents are added and no bleach or other chemicals are

${ }^{13}$ We are not aware of comparable discussions of machine-readable features for banknotes issued by monetary authorities outside the United States, although many authorities include machine-readable features in descriptions of their banknotes.

${ }^{14}$ The flax provides a "stiffness" to the notes that is absent in many 100 percent cotton notes and increases their durability. used to whiten the paper. As a result, unlike most printing papers, U.S. banknote paper does not fluoresce under UV light. When combined with raised texture provided by intaglio-printed images and numerals, the unique "feel" of U.S. banknotes is reported to be the most common method of counterfeit detection by the public and bank employees. For the visually impaired, this same feel is a tactile clue that helps to determine whether an offered banknote is genuine or not; it does not, however, assist the user with identifying the denomination of the note.

To foreshadow somewhat our discussion below of visual accessibility features, we note that the light green-yellow tint of U.S. banknote paper limits the contrast ratio that can be achieved between printed denomination numerals and their background. A higher contrast ratio improves the visual clarity of numerals (ideally, near black on white). But achieving higher contrast likely would require introducing bleach or other whiteners into the papermaking process. To the extent 
that such a change would alter the color and "feel" of U.S. banknote paper, it would remove one of the primary features used by the public, including the visually impaired, to detect counterfeit notes. To the extent the modified paper would display fluorescence, the change would also remove a test for the legitimacy of the banknote paper. At least with respect to banknote paper, anti-counterfeiting and visual accessibility considerations interact in a complex way, illustrating the potential trade-offs in currency design.

Preserving the traditional "look and feel" of U.S. banknotes has been an important consideration in recent design changes, and security features have been selected so as not to change the traditional look and feel of U.S. banknotes. The NRC lauds current security features as highly durable, low cost, odorless, and environmentally sound (that is, they do not depend on hazardous materials being included in the note) (NRC, 2006, p. 2). Further, many of the features are detectable by the naked eye.

All monetary authorities, on a continuing basis, monitor the effectiveness of current counterfeit deterrence features and seek to develop new ones. By all estimates, banknote design worldwide has been successful in deterring counterfeiting. ${ }^{15}$ In the United States, this work is coordinated by the Advanced Counterfeiting Deterrence Steering Committee, which lists effective currency design first among the three elements that comprise its counterfeit deterrence program (U.S. Treasury, 2006b, p. 7). ${ }^{16}$ Discussions that seek to measure counterfeiting must separate two concepts: (i) the fraction of outstanding banknotes that are counterfeit; and (ii) for the volume of notes that flow through a central bank's cash offices, what fraction are determined to be counterfeit. Counterfeit notes may be detected at any point in the economy,

\footnotetext{
${ }^{15}$ The appendix contains a list of internet sources for counterfeiting volume statistics of major world currencies.

${ }^{16}$ The second and third, respectively, are law enforcement and public education programs. The Advanced Counterfeit Deterrence Steering Committee is an interagency group that includes representatives from the Department of the Treasury (including the BEP), the Federal Reserve System, and the Department of Homeland Security's Secret Service. (Prior to creation of the Department of Homeland Security, the Secret Service was an agency of the Treasury Department.)
}

including by retail merchants, bank tellers, or central bank cash offices. Although central bank processing centers typically own the most sophisticated equipment, in the United States the majority of notes are detected by retail and bank personnel; again, the NRC notes that an incorrect "look and feel" is the most important detection method (NRC, 2006).

The flow of notes through central bank cash offices-relative to the outstanding number of notes in circulation-differs by denomination, by country, and through time, making it difficult to accurately infer the fraction of counterfeit notes in circulation. For almost all countries, the measured frequency of counterfeit notes is regarded as "low." For U.S. banknotes in circulation both inside the United States and abroad, the Treasury estimates that fewer than 1 in 10,000 are counterfeit. ${ }^{17}$ The Federal Reserve reports that it removed from circulation during 2005, and sent to the Secret Service, 6.4 notes per million processed, or a total of approximately 234,000 notes among the 36.5 billion pieces of currency processed. ${ }^{18}$ The incidence for the euro also is low: For 2005, the European Central Bank (ECB) reports detecting and confiscating from circulation 579,000 notes during the annual processing of approximately 30 billion notes (as of December 31, 2005, there were 10.4 billion euro notes in circulation). ${ }^{19}$ The $€ 50$ and $€ 100$ were the most frequently counterfeited notes.

\footnotetext{
${ }^{17}$ The Secret Service has jurisdiction over all matters related to counterfeit Federal Reserve notes. For discussion of methodologies used to estimate counterfeit currency worldwide, see the interagency reports issued by the U.S. Department of the Treasury (2000, 2003, and 2006b).

${ }^{18}$ During 2005, the Federal Reserve Banks processed 36.5 billion pieces of currency (Board of Governors of the Federal Reserve System, 2006). For the number of detected counterfeits, see U.S. Department of the Treasury (2006b, Table 6.3). As of December 31, 2005, 24.9 billion banknotes were in circulation, excluding $\$ 2$ notes (U.S. Treasury, 2006a). Of these, approximately 5.4 billion were $\$ 100$ notes, a large proportion of which are likely held abroad, and approximately 8.8 billion were $\$ 1$ notes, likely seldom counterfeited.

${ }^{19}$ See ECB (2006a, p. 102) and the biannual report of the ECB regarding counterfeiting, available at www.ecb.int/press/pr/date/ 2006/html/ pr060113_1.en.html. European newspaper articles suggest that counterfeiting decreased sharply following introduction of the euro, an example of the familiar result that design changes tend to slow counterfeiting. See also europa.eu/scadplus/leg/en/ s30003.htm, a website of the European Parliament, and Europol (2006a, 2006b)
} 
Changes in currency design are an important tool to deter counterfeiting. European newspaper articles suggest that counterfeiting rates for the euro are significantly lower than for the individual country banknotes that it replaced. News reports from Canada also illustrate the necessity for updating currency designs. Published reports for 2004 cited the counterfeiting of older-design notes as being at "dangerous" levels, with a rate of 4.7 counterfeit notes per 10,000 notes examined. ${ }^{20}$ Published reports affirm that the new-design notes with enhanced deterrence features sharply reduced the rate to 2.2 notes per 10,000 during the first eight months of 2006; features of Canadian banknotes are examined below. The Reserve Bank of New Zealand and the Reserve Bank of Australia reported to us that counterfeiting of polymer notes has been negligible, with ongoing activity limited to remaining paper notes in circulation; polymer notes are described in more detail below.

\section{CURRENCY DESIGN FEATURES FOR THE VISUALLY IMPAIRED}

Banknote designers worldwide are aware of the desire by the visually impaired to use currency in day-to-day transactions. Most banknote issuers consult regularly with advocacy organizations for the visually impaired. The principal issue for the visually impaired (persons with some recognizable visual field, including approximately 90 percent of persons with visual impairment in the United States), is to readily determine the denomination of banknotes during a transaction, say, at a distance of 16 to 24 inches. ${ }^{21}$ The principal issue for the blind (persons with no recognizable visual field) is the presence of tactile banknote

\footnotetext{
${ }^{20}$ More information is available from the Royal Canadian Mounted Police (www.rcmp-grc.gc.ca/scams/counter_e.htm) and various Canadian Broadcasting Corporation reports, including www.cbc.ca/ news/background/counterfeit/ and www.cbc.ca/canada/story/ 2006/11/20/counterfeit-bills.html.

${ }^{21}$ In our research, we have encountered several standards for classifying persons as "visually impaired" or "blind." The text in this paragraph uses one such classification. Below, we cite another in which blind is equated to a corrected visual acuity of less than $20 / 200$ and visually impaired as a corrected visual acuity of less than $20 / 40$.
}

features and/or machine-readable features that assist automated recognition of denomination by electronic currency readers. Accessibility features of currencies for selected countries are summarized in column 2 of Table 1.

As in most areas of economics, there is no free lunch in currency design: Those features that are of the highest value to the visually impaired also may, in some circumstances, impose significant costs on other currency users and handlers, including retail merchants, financial institutions, and high-volume currency processors. The application of economic benefit-cost analysis to select a set of features is not straightforward. For example, the benefiting group is not necessarily a closed set. Some features that assist the visually impairedsuch as large high-contrast numerals, note sizes that vary by denomination, and sharply different bright primary note colors-also assist normalsighted users to denominate banknotes under lowlight conditions or during hectic transactions. While the benefit is larger for the visually impaired, some benefit accrues to all persons using the notes. The benefits of features also varies by group: Low-cost features, such as larger denomination numerals, do not benefit the blind, whereas high-cost features, such as note sizes that vary by denomination, benefit the blind as well as other note users. Further, the visually impaired are not a homogeneous group and include persons born blind or who became blind during childhood, persons who became blind as adults, and individuals with limited visual acuity. Some know Braille, but many do not.

Previous studies of note design have consistently found that the design feature most valuable to the visually impaired is note sizes that vary by denomination. ${ }^{22}$ For example, in the summary section of its 1983 report to the Congress, the BEP wrote (BEP, 1983, p. 17):

\footnotetext{
22 See, for example, the BEP (1983) and the NRC (1995). Both these studies discussed additional proposed currency design features to assist the visually impaired, including Braille or Braille-like tactile features and notched edges or clipped corners. We do not discuss these features here because previous studies have concluded that the features deteriorate rapidly with the usage of the banknote. But, see the discussion of Canadian currency below, which uses non-Braille patterns of raised dots to assist the visually impaired.
} 
...[I]t would appear that the most broadly useful currency design change would be to produce Federal Reserve notes in a different size for each denomination. However, the effects of such a change on broad and diverse segments of the population would be monumental.

Although the report's authors ranked this design feature first when measured by its assistance to the visually impaired, they ranked it second overall due to its cost. Implementing a system of varying-size banknotes would affect all handlers of banknotes, including financial institutions, retail merchants, vending machine operators, high-volume banknote processors, the Federal Reserve System, the BEP, and the non-visually impaired. Instead, the authors ranked first among alternatives a handheld electronic note reader, in part because of its zero impact on most participants in the currency-based segment of the U.S. payment system (BEP, 1983, p.17).

With respect to the cost of implementing a system of varying-size banknotes where none exists, we are not aware of any published, public estimates for the total cost to an economy; undoubtedly, these costs would be dependent on the rate of implementation relative to the normal rate of replacement of depreciated equipment. Some published estimates are available for the BEP alone. In 1983, the Bureau estimated an initial start-up cost of \$25.6 million and annual incremental costs of $\$ 6.7$ million (BEP, 1983, p.12). In 2006, the Bureau estimated the implementation cost to be as high as $\$ 230$ million (Andrews, 2006). For perspective, these numbers might be compared to the cost of printing current U.S. banknotes. In 1983, the Federal Reserve System purchased 4.6 million banknotes from the BEP, for which the production cost (including certain adjustments for accounting changes and equipment purchases) was $\$ 23.00$ per 1,000 banknotes, a total of $\$ 105.8$ million (Volcker, 1986, Table 4). Relative to this figure, 1983's start-up costs equal 23 percent of the year's printing cost; the estimated annual incremental cost adds an additional 7 percent. If perhaps the start-up costs were to be amortized over a decade, annual currency manufacturing costs might increase by approximately 10 percent. Consider next 2006, in which the manufacturing cost for banknotes delivered to the Federal Reserve System was \$467 million (Board of Governors of the Federal Reserve, 2006b, Table 1). Relative to these figures, the 2006 startupcosts are approximately 49 percent of the 2006 printing cost. If amortized over a decade, the cost is approximately 5 percent per year, not including any incremental annual cost. ${ }^{23}$

Advances in technology promise increased ease of use for the blind and visually impaired. Canadian banknotes and all U.S. new-design banknotes issued since 1997, for example, contain specific machine-readable features that have been designed to assist the visually impaired. ${ }^{24}$ In Canada, through the Canadian National Institute for the Blind, blind and visually impaired persons

\footnotetext{
${ }^{23}$ The BEP sells banknotes to the Federal Reserve at a markup over the cost of manufacture. Although the Federal Reserve has some control over the quantities of notes ordered, the BEP sets the billing rates so as to recover its costs from the Federal Reserve (and other customers). For fiscal year 2006, BEP reports that the manufacturing cost for notes printed averaged $\$ 27.49$ per thousand (U.S. Treasury, 2007, p. 72). The BEP marks up notes (and other products), under Public Laws 81-656 (1950) and 95-81 (1997), to cover direct and indirect costs of operation, including administrative costs, and amounts sufficient to fund capital investments and meet working capital requirements (U.S. Treasury, 2007, p. 71). Denominationspecific BEP billing rates to the Federal Reserve System for notes in fiscal year 2006 ranged from a low of $\$ 43$ per thousand for $\$ 1$ and $\$ 2$ notes, to a high of $\$ 81$ per thousand for Series 2004 notes; for calendar year 2006, the Federal Reserve reports paying a volume-weighted average price of $\$ 55.74$ per thousand (Board of Governors, 2006b, Table 2). The \$1 and \$2 notes, which have not been redesigned, do not include the Series-1996 and Series-2004 design security features; $\$ 5$ notes include watermarks, but not color-shifting ink; Series-1996 \$100 notes include watermarks and color-shifting ink; and Series-2004 \$10, \$20, and \$50 notes include watermarks, color-shifting ink, background colors, and additional security features. The percentage ratios mentioned in the text would be smaller relative to the 2007 currency budget (assuming the costs didn't increase as well). For calendar year 2007 , the Federal Reserve reports a currency budget of $\$ 574.3$ million, an increase of $\$ 107.3$ million, or 23 percent. While the largest reason for the increase is a higher proportion of newer design notes that are more costly to produce, almost one-third (\$32.1 million) is to fund a decade-long BEP capital improvement plan which, during the first four years, will replace production equipment in Washington, D.C., including intaglio presses (some up to 26 years old) and overprinting equipment for some production lines (Board of Governors, 2006b).

${ }^{24}$ In response to our inquiries, other countries replied that their notes contain machine-readable features that could be used to assist the visually impaired, but that such features had not been included specifically to assist the visually impaired. For countries other than the United States and Canada, we are not aware of any available handheld currency authentication or denomination devices that use such features. The machine-readable features, of course, are of value to other currency handlers, including financial institutions, retail stores, and high-volume currency processors. See also Tables 1 and 2.
} 
can obtain at no cost a handheld banknote reader that signals denomination to the user via voice, tone, or vibration. This machine is produced by Brytech (www.brytech.com), which introduced a reader for Canadian currency in 1989 and a reader for U.S. currency in 1992. The readers are not identical: The reader for Canadian notes is smaller and contains features not included in the U.S. reader. In our research, we purchased a Brytech "Note Teller 2" reader for U.S. banknotes; the reader measures $6 \times 3 \times 1$ inches and weighs 8 ounces. ${ }^{25}$ The manufacturer does not publish recognition accuracy statistics for the reader (but offers a 30-day money-back guarantee). We asked approximately 20 of our colleagues to test their banknotes, both old and new designs, in a variety of conditions. Since the note reader "reads" the ends of the banknotes, it failed to read only those notes with folded corners and/or stains at the ends. ${ }^{26}$ Brytech staff noted that (i) although some customers find the U.S. currency reader satisfactory, others find it bulky and too expensive; and (ii) some users have reported problems using it with newer 1996 series and later currency designs. Although not inexpensive (at \$280 U.S.), perhaps technological advances will allow future price reductions. Recently, recognition of U.S. banknotes has been added to the Kurzweil-National Federation of the Blind reader. ${ }^{27}$ This reader, according to published documentation, captures and parses a digital image of an object, suggesting it is not using machine-readable features of the notes. We are aware of no published figures regarding accuracy of this device. Further, because it uses only a visual scan of the note, it perhaps is less valuable for authenticating than denominating notes. Although the currency feature will be of value to owners of the Kurzweil reader, the

\footnotetext{
${ }^{25}$ Our Note Teller 2 reader was the "standard" model with voice features. A recently introduced "enhanced" model includes the signal-by-vibration feature available on the Canadian currency model but not previously available on the U.S. model.

${ }^{26}$ The specific machine-readable features and technology used by Brytech are trade secrets.

${ }^{27}$ Details are at www.knfbreader.com. The web site says the Kurzweil reader makes a digital image of the object, then parses the digital image. Hence, the reader uses no machine-readable features of the notes.
}

reader's $\$ 3,500$ price very likely places it beyond the means of many visually impaired persons.

When considering costly design features that assist the visually impaired, an economic analysis of the benefit-cost trade-off depends, in part, on the number of affected persons. But, a great deal of uncertainty surrounds such estimates: It is difficult to measure accurately the number of Americans who will today and might in the future benefit from improved banknote visual accessibility. A study published in 2006 (Vitale et al., 2006) estimates the number of people with visual impairment to be about 14 million. ${ }^{28}$ The NRC (1995) reports, based on one widely used classification, that as of the early 1990s approximately 9 million Americans were classified as blind or visually impaired. The NRC (1995) report cautions that traditional criteria may greatly understate the true extent of impairment because the determination is made by measuring visual acuity in laboratory settings under ideal lighting and highcontrast conditions. To read text rapidly and accurately in practical situations such as occur at a retail cash register often requires numerals three to five times larger than the sizes commonplace in laboratory visual acuity tests-if used, such a criterion would classify millions of additional persons as visually impaired. In addition, many studies, including NRC (1995), have noted that the design of visually accessible currency is as much an age-related issue as a vision-related issue. Looking forward, the aging of the world's population portends visual problems; many conditions related to aging reduce vision, including macular degeneration, glaucoma, and retinitis pigmentosa. In addition, contrast sensitivity and pupil size tend to decrease with age: At 80 years old, the eye often admits only one-quarter the light admitted for a 20-year old. Combined with other age-related factors, the result is "a severe reduction in visual performance under adverse lighting conditions for older people." ${ }^{29}$ (The first

\footnotetext{
${ }^{28}$ This figure would correspond to the number of U.S. residents aged 12 years or older with visual acuity of $20 / 50$ or worse. The study also found that approximately 83 percent of those people estimated to be visually impaired would qualify for a driver's license if they had corrective lenses.

${ }^{29}$ NRC (1995).
} 
formal study of the visual accessibility of U.S. banknotes, reviewed below, was conducted at the behest of the U.S. House of Representatives committee on aging.) The National Eye Institute (2002) estimates that the number of Americans who are blind (that is, best corrected visual acuity of 20/200 or less in the better-seeing eye) and have low vision (best corrected visual acuity of $20 / 40$ or less) due to age-related eye diseases will double over the next 30 years.

Recognizing these technical shortcomings with respect to measuring visual impairment, the NRC (1995, p. 6) argued for an aggressive stance on vision enhancements: Small enhancements, adequate in laboratory settings, are likely to produce designs that are inadequate in practical settings. Among their conclusions was this:

It is clear that a major need exists for a better means of banknote denomination for the 3.7 million Americans with visual disabilities, with the goal of giving this population the full access to currency handling available to the rest of society and to visually disabled people in other countries. In addition, due to the increasing number of older individuals with impaired vision due to minor eye disease or the normal aging process, such features would be of great benefit to a far wider population than that represented by the current statistics on blindness and low vision. Certain new features, such as color and size, and enhanced existing features, such as larger numerals of higher contrast, would also benefit those with normal vision by making denomination more rapid and convenient for all.

Visual accessibility features of banknotes issued by several member countries of the Bank for International Settlements' Committee on Payment and Settlement Systems (including the United States) are summarized in Table 1. Features include varying note sizes by denomination; oversize numerals to indicate denomination; highcontrast numerals printed in dark inks against light backgrounds, or the reverse; different principal colors for different denominations; and, tactile features such as embossed numerals or patterns of recessed or raised dots.

In Europe, the designers of euro notes at the ECB "consulted extensively" on the design of the euro banknotes with the European Blind Union and the World Blind Union, the latter a worldwide umbrella organization for advocacy groups of the blind and visually impaired. A number of their specific efforts are described on the web site of the European Blind Union (www.euroblind.org) under the "Access to Information" heading. Special features include (i) sizes that vary by denomination, (ii) "striking" "clearly contrasting" colors, (iii) denominations printed in large numerals, (iv) high-relief raised intaglio printing, (v) and special tactile marks printed in intaglio along the edges of $€ 200$ and $€ 500$ banknotes. ${ }^{30}$

There is a similarly long history in the United States of interaction between currency designers at the BEP and advocacy groups for the visually impaired. The American Council of the Blind reportedly has submitted suggestions regularly to the BEP since at least 1972 (NRC, 1995). In 1983, the first (to our knowledge) formal study of the visual accessibility of U.S. banknotes was conducted by representatives from the American Council of the Blind, the Federal Reserve System, the BEP, and the U.S. Secret Service, at the request of Congressman Edward Roybal, chair of the U.S. House Committee on Aging. The subsequent report is BEP (1983). ${ }^{31}$ In addition to being the first formal study, the 1983 report is important because its issues resurface in more recent discussions. In its introduction, the report says that "since the early 1970s" there has been a "significant interest" in designs for U.S. currency to assist the visually impaired-that is, since the Netherlands introduced in January 1971 innovative banknotes with raised (embossed) tactile symbols for each denomination. The report continues by citing unpublished 1976 and 1980 studies by the BEP regarding methods for easing the recognition of a banknote's denomination. The 1976 study, it says, examined the incorporation of

\footnotetext{
${ }^{30}$ See www.ecb.int/bc/euro/banknotes/visually/html/index.en.html, as of July 2007 . The $€ 5, € 10, € 20, € 50, € 100, € 200$, and $€ 500$ notes, respectively, feature the colors gray, red, blue, orange, green, yellow, and purple.

${ }^{31}$ This report is available from the Federal Reserve Bank of St. Louis in its FRASER archive: http://fraser.stlouisfed.org/historicaldocs/ tresbep/download/30353/study_of_mechanisms.pdf.
} 
Braille markings in currency, and the 1980 study examined "notching" and/or cutting the corners of banknotes. ${ }^{32}$

The 1983 report's original research is presented in three parts. First, the staff reviewed the currencies of 54 countries (including the United States) for characteristics that would assist denomination by the visually impaired and asked each country to provide information on the performance of the features; five countries responded. The report's summary of the comments notes that "few countries have intentionally designed currency for this purpose" and that the comments received suggest that none are "completely satisfactory." Second, technical staff from the BEP evaluated "selected features" with respect to cost and usefulness to the visually impaired. Although details are not provided, the report says that the staff affirmed that commonly proposed design features-including colors that varied by denomination, large and clear numerals, note sizes that varied by denomination, cut corners or notches, and Braille-like tactile features-likely would assist denomination by the visually impaired. Costs for implementing various combinations of these features in U.S. banknotes ranged from $\$ 600,000$ to $\$ 6$ million per year. Third, the staff explored the feasibility of an automated portable currency reader. Noting that such a device already was available but citing its bulk and expense, the staff recommended that funding be sought to develop a handheld electronic currency reader able to denominate currency. Such a device would assist both the visually impaired and the blind, while requiring at most only modest design changes for U.S. banknotes.

Chronologically, the next formal U.S. study of visual accessibility was commissioned by the BEP to the NRC of the National Academy of Sciences (NRC, 1995). The NRC was charged with several tasks:

- assess features that could be used by people who are visually disabled to recognize, denominate, and authenticate banknotes;

\footnotetext{
${ }^{32}$ The outcome of such experiments in not noted in BEP (1983). With respect to notches and cut corners, the report does note that the Federal Reserve and U.S. Secret Service "expressed fundamental concerns" that problems might arise during a transition period.
}

- recommend features that could reasonably be incorporated into banknotes using available technology;

- suggest strategies that should be instituted to make the recommended features more effective;

- and identify research needs in particularly promising areas that could lead to attractive future approaches.

The 1995 NRC study is lengthy and complex, considering in detail both practical and technical issues. This quote summarizes the NRC's view of the state of U.S. currency design in 1995 (NRC, 1995, Chap. 2, p. 13):

The United States is alone in issuing paper currency bills in which all denominations are of identical size and color. The numbers on the corners of the bills are small and of low contrast, making them difficult to read by people with impaired vision. For everyday transactions, U.S. paper currency possesses no nonvisual identifying features, rendering it impossible for blind people to denominate bills without assistance. The lack of distinctive visual features and the total absence of nonvisual features for the common user constitute a hindrance to commerce and daily living for millions of visually disabled people. In addition, the lack of distinctive features results in problems of denomination for a much wider population with mild visual impairments, including those impairments acquired during the normal aging process, and for anyone in a poorly lit environment.

The study eventually recommends four features technologically available in 1995:

- banknote sizes that vary by denomination;

- large, high-contrast numerals on a uniform background (for large numerals, the Committee recommended numerals larger than half the note's height of approximately $65 \mathrm{~mm}$ );

- different predominant colors for each of the six denominations being printed;

- and embedded features to assist development of effective, low-cost devices for examining banknotes. 
These recommendations are largely the same as those identified in BEP (1983). Consistent with that study, the NRC (1995) concludes that varying banknote sizes by denomination is the most effective feature to assist denomination by both the blind and visually impaired. The study notes, however, that this is the most costly feature to implement. Further, the change would primarily benefit the blind, who are approximately 10 percent of all visually impaired persons in the United States. In contrast, other features-such as larger numerals and different primary colors-would benefit all banknote users by speeding identification of denomination, particularly in low-light situations. Regarding cost, the committee concluded that the costs to redesign U.S. banknotes and modify equipment to handle them (especially in varying sizes) would be high-but the Committee did not temper its recommendations with regard to these costs because a major redesign already was planned during 1996-2001. Instead, the Committee recommended that these features be incorporated during the 1996-2001 currency redesign cycle.

Since 1995, the BEP has introduced two new designs for U.S. banknotes, each containing features to improve accessibility for the visually impaired. These designs are frequently referred to as the Series 1996 "New Currency Design" and Series 2004 "New Color of Money" designs. ${ }^{33}$ Series 1996-design notes were introduced beginning with the $\$ 100$ note in March 1996, followed by the $\$ 50$ note in October 1997, the $\$ 20$ note in the fall of 1998, and the $\$ 5$ and $\$ 10$ notes in May 2000. Series 2004-design notes were introduced with the $\$ 20$ note in October 2003, followed by the $\$ 50$ note in late 2004 and the $\$ 10$ in March 2006 (the $\$ 5$ note is anticipated in early 2008). These new designs include a number of security and accessibility features that are visible and useful without machine assistance. For visual accessibility, the Series 1996 design, beginning with the $\$ 50$ note, introduced an enlarged, $14 \mathrm{~mm}$ tall denomination numeral in the lower right

33 The BEP refers to additional series (for example, Series 1999, 2001, and 2003) to denote changes in the signatures on the notes; these were not design changes, however. See BEP (2004) and www.moneyfactory.gov/section.cfm/4/27/. corner of the notes' reverse side. ${ }^{34}$ The presidential portrait also was enlarged. A machine-readable feature to facilitate development of handheld scanning devices for the blind and visually impaired has been included in all new-design banknotes issued since 1997. The Series 2004 design introduced an additional accessibility feature, subtle background colors:

For the first time since the Series $1905 \$ 20$ Gold Certificate, the new currency featured [sic] subtle background colors, beginning with the new $\$ 20$ note on October 9, 2003. In this series, different colors are used for different denominations. This will help everyoneparticularly those who are visually impairedto tell denominations apart. The $\$ 20$ note features subtle background colors of green, peach and blue, as well as symbols of freedom representing icons of Americana-in the case of the $\$ 20$ note, images of the American eagle.

It is of interest to compare the features of these newer banknotes designs to recommendations made in the previous 1983 and 1995 studies. In its most recent report, the NRC (NRC, 2006, p. 10) concludes that these features "do not provide adequate differentiation for many visually impaired individuals and provide no method of differentiation for blind persons." This perhaps was not unexpected. Putting aside the enlarged portrait, the Series 1996 design added a single truly usable feature for the visually impaired: the enlarged, $14 \mathrm{~mm}$ denomination numeral in the lower right corner of the reverse. But, the NRC previously noted that a numeral this size is near the visual limit for someone with $20 / 400$ acuity when viewed at a reading distance of 16 inches (NRC, 1995): The NRC recommended a numeral more than twice as large. As an example, the NRC cites studies regarding denomination recognition of current $\$ 1$ and $\$ 10$ banknotes displaying $12 \mathrm{~mm}$-tall numerals on their fronts, which standard acuity tests suggest should be

\footnotetext{
${ }^{34}$ U.S. banknotes typically display denomination in numerals of between $8 \mathrm{~mm}$ and $12 \mathrm{~mm}$ tall. On $\$ 1$ and $\$ 10$ notes, for example, the upper front numerals are approximately $12 \mathrm{~mm}$ tall, while the numerals on the lower front and on the reverse are approximately $8 \mathrm{~mm}$ tall. The $\$ 100$ note does not have the large high-contrast numeral.
} 
adequate for many visually impaired-in fact, users with measured acuity less than 20/60 have difficulty recognizing such numerals at the distances of 16 to 24 inches that are common in retail cash transactions. With respect to color, the NRC (NRC, 1995) recommended that at least one side of each denomination's design feature a single prominent color, not subtle shades of background colors. Specifically, they wrote:

Most other countries also use different predominant colors for each denomination. The simple detection color is faster than finding and reading printed numbers, especially for those with poor letter acuity. It should be noted, however, that many people with low vision have difficulty in discriminating subtle shades of color and that color cues are generally less obvious at low levels of illumination. Consequently, any color features should use clearly distinguishable colors. (NRC, 1995, p. 25)

We display Series 2004 notes in Figure 11 and leave final judgment to the reader. Neither NRC report, however, addressed the trade-off between improved visual accessibility and concerns for counterfeit deterrence and widespread recognition and acceptance, especially outside the United States. We are not aware of any study that addresses this trade-off.

Current improvements in technology portend new features that will be of benefit to the blind and visually impaired. The NRC's 2007 report (NRC, 2007), commissioned by the BEP, concludes that advances in currency substrates will be the only effective future deterrent to counterfeiting as improving digital technology eases image reproduction. But the report also contains fascinating glimpses of new substrates that might permit designers to include innovative features to assist the visually impaired denominate currency. "Shape memory" materials, for example, are ones that allow an object's shape to change when subject to stress and return to the original shape when stress is released. Similarly, embedded piezoelectric crystals allow an object's features to change when an electric current is applied. Conceptually, at least, such materials could allow embedded tactile denomination markings-say, similar to those in Canadian and Japanese notesto "appear on demand" when a note is stretched or when it is energized by a battery operated device. Unlike current tactile markings, which degrade with abrasion, such markings perhaps could last the lifetime of the note. Technology also suggests the possibility of notes that change color when subject to an electric current, aiding both counterfeit deterrence and the long-sought goal of varying banknotes' primary colors by denomination: For most users, the appearance of U.S. banknotes would be unchanged, while the visually impaired could energize special visual features as required. More analysis of such materials and features will be required before they could be implemented, and an international education program might be required if the "look and feel” of U.S. banknotes is affected by changes in substrates. But the promise intrigues.

\section{WHAT DO OTHER COUNTRIES DO? SECURITY AND ACCESSIBILITY FEATURES}

Banknote designers worldwide seek to include features both to deter counterfeiters and assist the visually impaired. Most banknotes incorporate several security features, including holograms, microprinting, serial numbers, and watermarks. Most notes also include one or more visual accessibility feature, including different sizes and principal colors for different denominations, oversize high-contrast numerals, and tactile features such as embossed numerals or recessed/raised dots. Among major currency issuers worldwide, only banknotes issued by Canada and the United States do not differ in size by denomination. In this section, we explore the features of currency issued by nine industrialized countries and the euro zone.

In their 1995 study, the NRC surveyed 171 currency-issuing authorities (NRC, 1995). In many countries, security and accessibility features were regarded as complementary. More than 120 countries varied note sizes by denomination, 24 featured oversized denomination numerals, and 167 used different primary color schemes for different denominations. Among larger countries, only the 
Table 2

\section{Summary of Currency Design Features Intended To Assist the Visually Impaired, Major Issuing} Authorities

\begin{tabular}{|c|c|c|c|c|c|}
\hline Issuing authority & $\begin{array}{l}\text { Primary colors } \\
\text { that differ by } \\
\text { denomination* }\end{array}$ & $\begin{array}{c}\text { Size that } \\
\text { differs by } \\
\text { denomination }\end{array}$ & $\begin{array}{l}\text { Tactile } \\
\text { recognition } \\
\text { symbols }\end{array}$ & $\begin{array}{c}\text { Certain } \\
\text { oversize } \\
\text { numerals }{ }^{\#}\end{array}$ & $\begin{array}{l}\text { Machine-readable } \\
\text { features for } \\
\text { banknote readers }\end{array}$ \\
\hline Australia & $\mathrm{Y}$ & $\mathrm{Y}$ & $\mathrm{Y}$ & $\mathrm{Y}$ & $\mathrm{N}$ \\
\hline Canada & $\mathrm{Y}$ & $\mathrm{N}$ & $\mathrm{Y}$ & $\mathrm{Y}$ & $\mathrm{Y}$ \\
\hline Euro Currency Area $^{\dagger}$ & $\mathrm{Y}$ & Y & $\mathrm{Y}$ & Y & $\mathrm{N}$ \\
\hline Hong Kong SAR & Y & $\mathrm{Y}$ & $\mathrm{Y}$ & Y & $\mathrm{N}$ \\
\hline Japan & $\mathrm{Y}$ & $\mathrm{Y}$ & $\mathrm{Y}$ & $\mathrm{N}$ & N \\
\hline Singapore & Y & $\mathrm{Y}$ & $\mathrm{Y}$ & Y & $\mathrm{N}$ \\
\hline Sweden & Y & $\mathrm{Y}$ & $\mathrm{Y}$ & Y & $\mathrm{N}$ \\
\hline Switzerland & $\mathrm{Y}$ & $\mathrm{Y}$ & $\mathrm{Y}$ & $\mathrm{Y}$ & $\mathrm{N}$ \\
\hline United Kingdom & $\mathrm{Y}$ & $\mathrm{Y}$ & $\mathrm{N}$ & $\mathrm{Y}$ & $\mathrm{N}$ \\
\hline United States $§$ & $\mathrm{Y} / \mathrm{N}$ & $\mathrm{N}$ & $\mathrm{N}$ & $\mathrm{Y}$ & $\mathrm{Y}$ \\
\hline
\end{tabular}

NOTE: *In this table, we define the primary color of the banknote as that used for the prominent portrait (if any), borders, and the denomination numerals, or, in some cases, the dominant color of the note. Because we are not aware of any current cross-country

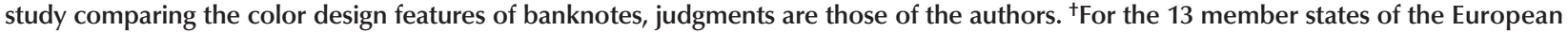
Union participating in the single currency. ${ }^{\ddagger}$ Bank of Japan notes use less intense, near-pastel colors. Although each denomination uses a different dominant color for the portrait, background, and numerals, some readers of previous versions of this article felt that the differences are not sufficient to support our conclusion. We disagree. \$Currently issued Series 2004 U.S. banknotes in denominations of $\$ 10, \$ 20$, and $\$ 50$ feature different dominant colors. The U.S. Bureau of Engraving and Printing has announced that new designs for the $\$ 5$ and $\$ 100$ notes also will feature differing dominant colors. All currently issued notes except the $\$ 1$ note feature a large denomination numeral on the reverse. The $\$ 1$ note features a prominent "ONE" in the center of the reverse. "Including both embossed symbols and patterns, and special high-relief intaglio printing (if cited by issuing authority as a visual accessibility feature). \#Included if cited by issuing authority as a visual accessibility feature.

United States and Canada did not vary the size of their notes by denomination.

Table 1 compares and contrasts banknotes' characteristics relative to those of an "ideal currency." Table 2 narrows the comparison to five visual accessibility features: colors that vary by denomination, sizes that vary by denomination, inclusion of tactile recognition symbols, oversize denomination numerals, and machine readability features for banknote readers. (The features shown in the tables are as reported by the respective monetary authorities in public documents. We have not undertaken any independent scientific investigation regarding the features of the banknotes.) In short, we find that no currency includes all five features. Seven of the ten currencies include four features, and three currencies include three features.
Currency images reproduced in this article are as accurate as can be achieved with modern high-volume printing but do not necessarily match colors in the original banknotes. For some notes, to deter counterfeiters, designers select colors that cannot be accurately reproduced by office copiers, printers, and high-volume offset presses.

\section{Australia $^{35}$ (see Figure 2)}

The Reserve Bank of Australia is responsible for printing, issuing, reissuing, and canceling Australian notes (currency name: Australian dollar; currency code ${ }^{36}$ : AUD; currency symbol:

\footnotetext{
${ }^{35}$ Additional information may be found at www.rba.gov.au/ CurrencyNotes/.

${ }^{36}$ Currency codes for each country discussed correspond to the International Organization for Standardization ISO 4217 threeletter codes. See www.iso.org/iso/en/CatalogueDetailPage. CatalogueDetail ?CSNUMBER=34749\&ICS1 $=3 \& I C S 2=60 \& I C S 3=$.
} 
\$ or AU\$). (Notes are printed by Note Printing Australia Limited, a subsidiary of the Reserve Bank.) Since 1996, all Australian banknotes have been printed on a polymer substrate. ${ }^{37}$ The substrate is manufactured by Securency Pty Ltd., a joint venture between the Reserve Bank and Innovia Films. The substrate is created by coating a clear polypropylene film with an opacifying ink. The "press ready" substrate is supplied to Note Printing Australia. Traditional security printing processes are used to print the notes, including offset and intaglio. As a final step, a clear overcoat is applied to the notes. It is possible to achieve the same intaglio height on polymer substrate as on paper, by depositing a greater quantity of ink. ${ }^{38}$ When "blind embossing" polymer (using an uninked intaglio plate), a greater degree of emboss can be achieved in the substrate.

According to the Reserve Bank of Australia, the counterfeiting rate for Australian banknotes is "very low," averaging between five and six counterfeits per million notes in circulation in recent years. Almost all counterfeits of Australian notes are printed on paper rather than polymer. Yet, even polymer notes are not immune to counterfeiting attempts; in March 2006, Interpol seized more than AU\$5 million of such notes in Colombia, a popular location for counterfeiters. ${ }^{39}$ Such attempts appear to be rare; so far as we are aware, no such notes were placed into circulation.

Although more costly than paper notes, polymer notes are more durable (they last at least four times longer), more difficult to counterfeit, and recyclable. Australian banknotes vary in color and length according to denomination. The AU\$5 banknote is the shortest ( $130 \mathrm{~mm}$ by

\footnotetext{
${ }^{37}$ Since 1998, New Zealand banknotes have been produced in Australia by the same process.

${ }^{38}$ The height of the relief on polymer notes has encountered some controversy. With paper substrate, a somewhat higher initial relief may be obtained than on polymer, but advocates of polymer substrates have argued that the higher relief degrades quickly to a lower relief than on polymer notes. We take no position on this, leaving debates regarding the exotic technical details of intaglio printing on alternative substrates to others. See, for example, Coventry (2001), only one of many papers on this topic.

${ }^{39}$ See www.interpol.int/Public/FinancialCrime/CounterfeitCurrency/ recentEvents.asp or the BIS-G10 Central Bank Counterfeit Deterrence Group (CBCDG) joint counterfeit deterrence task force, www.rulesforuse.org/pub/index.php?lang=en\&page=pressreleases.
}

$65 \mathrm{~mm})$, and the AU\$100 banknote is the longest (158 $\mathrm{mm}$ by $65 \mathrm{~mm}$ ).

\section{Security Features}

Among the security features included in the banknotes are

- Clear window with "blind" embossing and a printed image

- See-through registration device

- Shadow image (similar to a watermark)

- Intaglio printing

- Background print (including screen traps)

- Microprinting

- Machine-readable features including UV fluorescence, infrared, and magnetics/inks.

\section{Accessibility Features}

The Reserve Bank of Australia consulted with a number of entities representing the visually impaired in designing the polymer note series. Among the accessibility features of the banknotes are

- Lengths that vary by denomination

- Strong color contrasts that vary by denomination

- Bolder numerals

Raised intaglio printing of denomination numerals, portraits, and other elements is both a security and accessibility feature. In addition, Blind Citizens Australia provides, free of charge, a credit-card size device to measure note length and distinguish between denominations. So far as we are aware, no handheld reader is available that uses the included machine-readable features to assist the visually impaired.

\section{Canada (see Figure 3)}

The Bank of Canada has sole responsibility for issuing, designing, producing, and distributing Canadian banknotes (currency name: Canadian dollar; currency code: CAD; currency symbol \$ or C\$). ${ }^{40}$ The Bank of Canada's first banknote series was printed on a combination of flax and

40 Additional information may be found at www.bankofcanada.ca/ en/banknotes/. 
Figure 2

Australia: Security and Accessibility Features

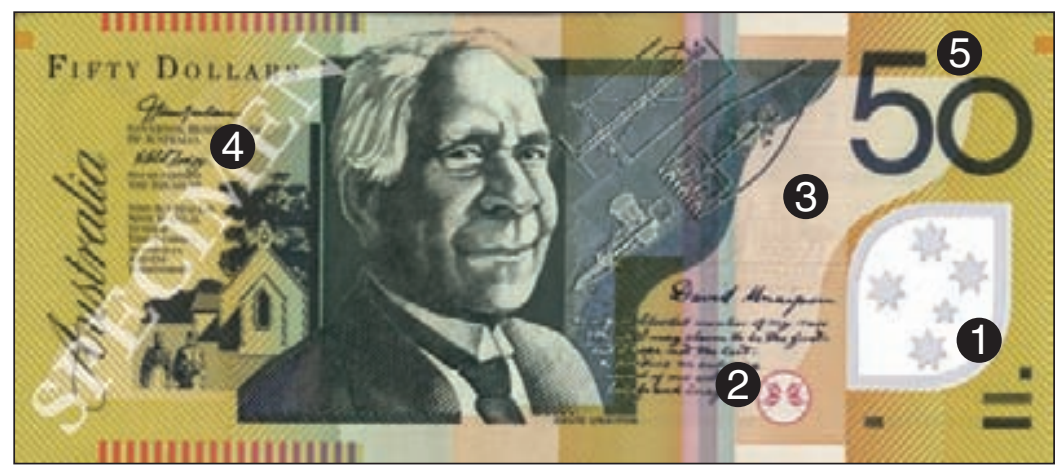

Front

Security Features

1. Clear window

2. See-through registration device

3. Shadow image

4. Microprinting

Accessibility Features

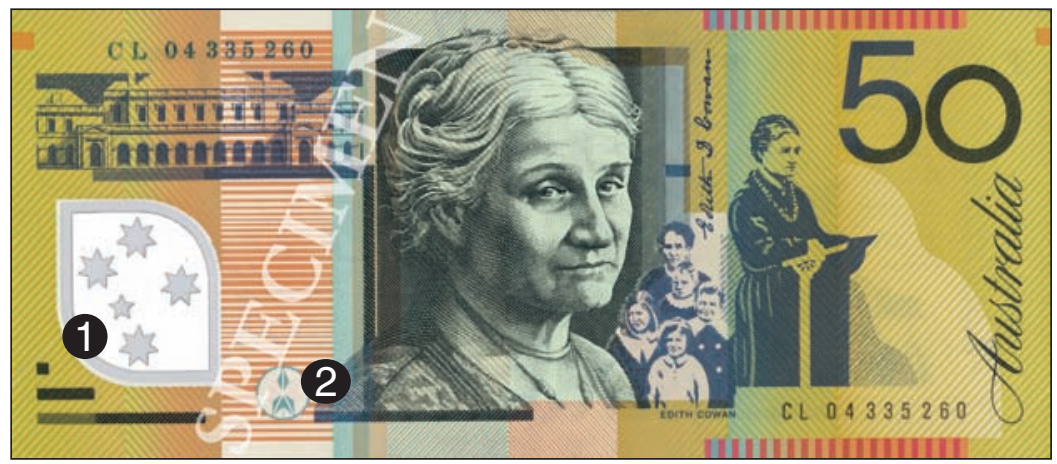

5. Bolder numerals

- Length differentials by denomination

- Strong color contrasts

Back
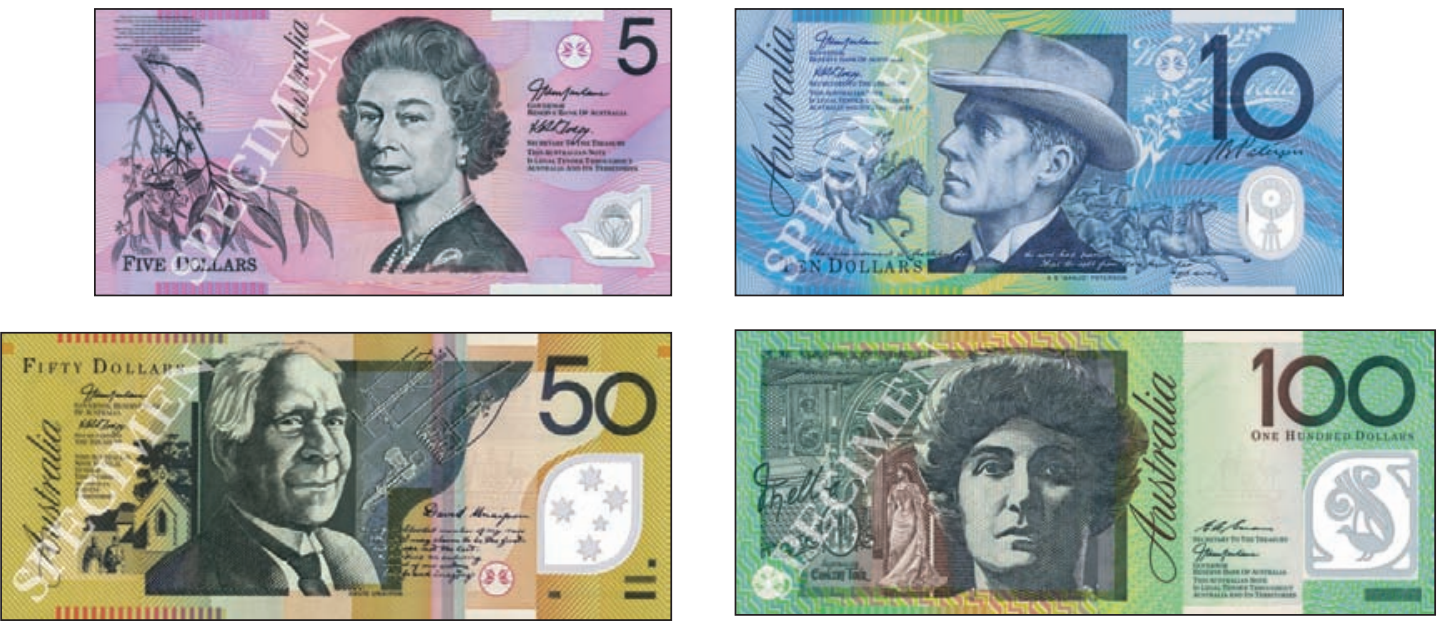

NOTE: See Tables 1 and 2 and the appendix for a complete listing of security and accessibility features. SOURCE: Reserve Bank of Australia. 


\section{Figure 3}

\section{Canada: Security and Accessibility Features}

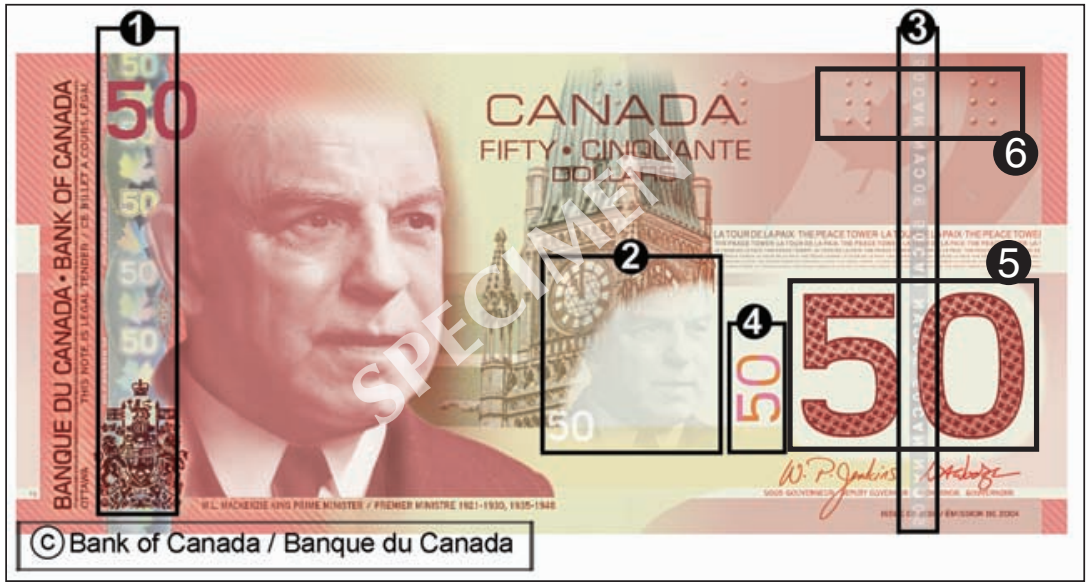

Front

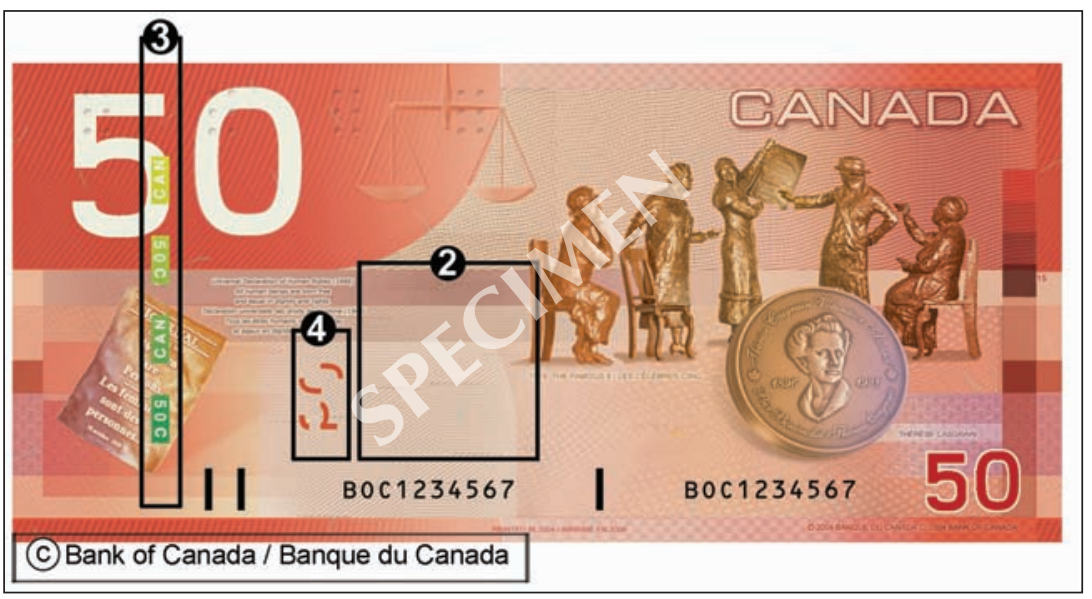

Security Features

1. Metallic strip (holographic stripe)

2. Ghost image (watermark)

3. Dashes (security thread)

4. See-through number

5. Raised ink (intaglio printing)

Accessibility Features

5. Large, high-contrast numerals

6. Tactile feature

- Varying color by denomination

Back
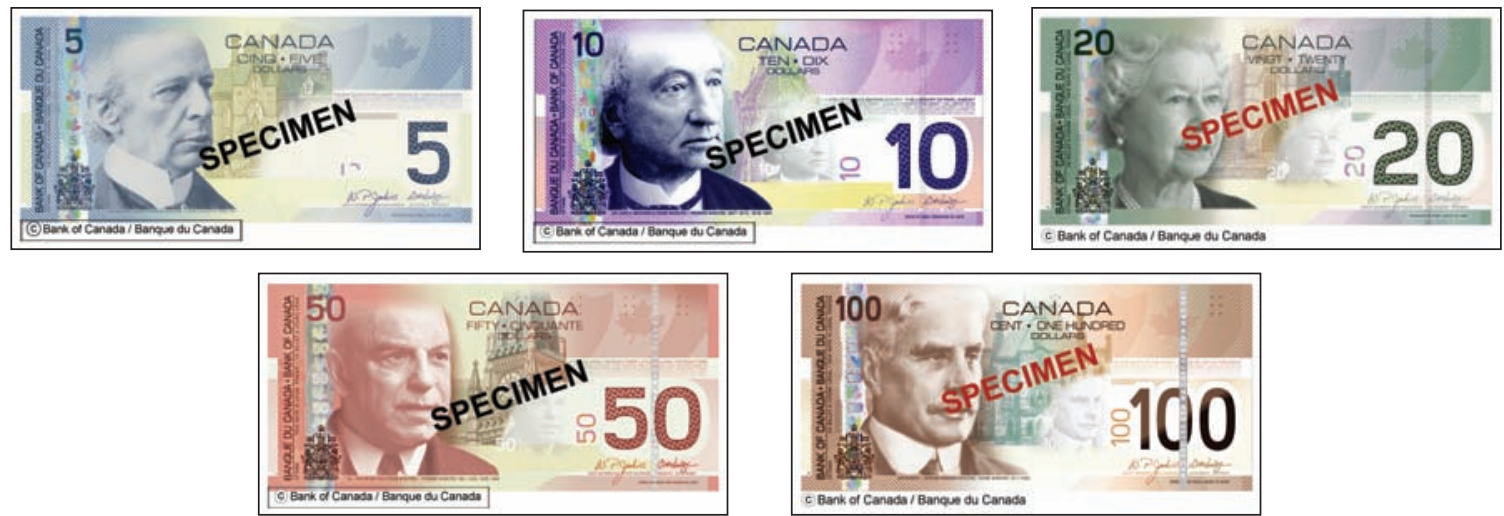

NOTE: See Tables 1 and 2 and the appendix for a complete listing of security and accessibility features. SOURCE: Bank of Canada. 
cotton paper with the same nominal composition as U.S. banknote paper. Since 1983, however, Canadian banknotes have been printed on 100 percent cotton paper to conform to Quebec environmental laws on flax use.

Canadian banknotes are uniform in size but vary in color by denomination. Notes measure approximately 6 inches long by 2.75 inches wide. ${ }^{41}$

The production cost of Canadian banknotes is approximately 9 Canadian cents per note. The estimated life of the banknotes by denomination is as follows:

- C\$5: 1 to 2 years

- C\$10: 1 to 2 years

- C\$20: 2 to 4 years

- $\mathrm{C} \$ 50: 4$ to 6 years

- C\$100: 7 to 9 years

According to the Bank of Canada, Canadian counterfeit notes make up a very small percentage of notes in circulation. ${ }^{42}$ The most recently issued banknote series-entitled the Canadian Journey series-contains both enhanced security features to deter counterfeiting and tactile features to aid the visually impaired.

The Bank of Canada consulted with the Canadian National Institute for the Blind, the Canadian Council for the Blind, and the blind and visually impaired community in the design of their Canadian Journey and Birds of Canada bank note series to help the blind and visually impaired with recognition of bank notes by sight, touch, or electronic devices. The Bank of Canada, in collaboration with the blind and visually impaired community, has encouraged the development of machines to denominate Canadian notes.

\footnotetext{
${ }^{41}$ With the exception of the 1935 and 1937 banknote issues, which are 6 inches by 2.875 inches.

42 The Royal Canadian Mounted Police's Bureau for Counterfeit and Document Examinations estimates that in 2005, the volume of counterfeit notes passed and seized was approximately 422,489 of 1,501,743,000 notes in circulation, or 0.00028percent of the total notes in circulation (www.rcmp.ca/factsheets/fact_counterfeit_e. $\mathrm{htm})$. The figure was even lower in 2006: According to the Bank of Canada, 313,207 counterfeit notes were passed and seized, from a total of $1,567,318,000$ notes in circulation, or 0.00020 percent.
}

Through the Canadian National Institute for the Blind, blind and visually impaired persons can obtain (at no cost) a handheld banknote reader that signals denomination to the user via voice, tone, or vibration.

The tactile denomination scheme, of Canadian invention, consists of sets of raised dots that vary in position and number according to denomination. The dot system is not Braille which, contrary to public impressions, is not known by all the blind. The basic "symbol" in the scheme is a tightly spaced rectangular block of six dots-the number and placement of such blocks indicates the denomination. The C\$5 note has one block, for example, while the C $\$ 20$ note has three such blocks separated by a smooth surface. Canadian banknotes also include intaglio printing of the denomination numerals, which doubles as a security and accessibility feature.

\section{Security Features}

- Holographic stripe

- Watermark portrait

- Windowed color-shifting thread

- See-through number when note is held to the light

- Raised ink (intaglio printing)

- Fine-line patterns

- Microprinting

- Fluorescence, presence of elements only visible under UV light

- Serial number

- Unique, difficult-to-reproduce colors

\section{Accessibility Features}

- Primary colors that vary by denomination

- Tactile symbols embossed and back-coated for durability

- Large high-contrast denomination numerals

- Machine-readability feature, free banknote readers

\section{Euro Currency Area (see Figure 4)}

The euro banknotes (currency name: Euro; currency code: EUR; currency symbol: $€$ ) were introduced as legal tender in the Eurosystem on 
January 1, 2002. ${ }^{43}$ The ECB and the national central banks (NCBs) of the participating countries have the right to issue euro banknotes, but in practice only the NCBs issue banknotes. ${ }^{44}$ Banknote production is pooled between the NCBs, and the approximate cost is $€ 0.08$ per note. ${ }^{45}$

Euro banknotes are made of 100 percent cotton. Banknotes vary in height, length, and color according to denomination. The $€ 5$ banknote is the smallest in size, measuring $120 \mathrm{~mm}$ long by $62 \mathrm{~mm}$ wide; the $€ 500$ banknote is the largest, measuring $160 \mathrm{~mm}$ long by $82 \mathrm{~mm}$ wide. The estimated life of euro banknotes by denomination is as follows ${ }^{46}$ :

- $€ 5: 1.2$ years

- $€ 10: 1.2$ years

- €20: 1.4 years

- €50: 3.3 years

- €100: 7.5 years

- €200: 10.4 years

- €500: 23.1 years

The weighted average lifetime for all denominations is two years.

The ECB has consulted with the European Blind Union since the beginning of the euro note design phase in 1995 to ensure notes are highly accessible to the blind and visually impaired.

Each banknote-whether $€ 5$ or $€ 500$ - had to be readily identifiable by people with residual or no sight. For example, the differences in height

\footnotetext{
${ }^{43}$ The Eurosystem comprises the ECB and the NCBs of the European Union member states that have adopted the euro. Currently, 13 member states of the European Union participate in the single currency—namely, Belgium, Germany, Greece, Spain, France, Ireland, Italy, Luxembourg, the Netherlands, Austria, Portugal, Slovenia, and Finland.

${ }^{44}$ Additional information may be found at www.ecb.int/bc/euro/banknotes/html/index.en.html.

${ }^{45}$ The NCBs authorize privately and publicly owned production facilities to print banknotes, and each facility prints one or two of the seven denominations. Once they have printed the banknotes, the issuing central banks exchange them. This process increases efficiency and quality control. The ECB monitors the stocks of the banknotes.

${ }^{46}$ Data furnished by the ECB. Life span of the banknotes is calculated by dividing, for each denomination, the average circulation of banknotes during the previous 12 months, by the number of banknotes determined to be unfit during the previous 12 months.
}

between the lower, more commonly used denominations were quite distinct. The $€ 100, € 200$, and $€ 500$ banknotes were made the same height-to facilitate automatic handling-but repetitive embossed patterns were placed on the $€ 200$ and $€ 500$ banknotes to differentiate them.

Large and bold value numerals were placed in a standard position throughout the series, on both sides, and sharply contrasting colors were used. They were derived principally from the color wheel of the Swiss painter and art teacher Johannes Itten (1888-1967). The colors chosen for successive denominations were taken from opposing segments of the color wheel and thus strongly contrast with each other. The same is true for denominations that have digits in common, like the red $€ 10$ and green $€ 100$ banknotes (ECB, 2007).

While euro banknotes include denominationspecific machine-readable features intended to assist authentication and denomination by third parties (primarily high-volume currency processors and banknote equipment manufacturers), so far as we are aware, electronic banknote readers have not been developed to assist visually impaired individuals.

Counterfeiting of euro banknotes is reportedly low. For 2003-06, the ECB reports detecting and confiscating from circulation approximately 600,000 notes annually (with approximately 10 billion in circulation) (ECB, 2006b). Figures on notes confiscated by law enforcement before entering circulation are confidential.

\section{Security Features}

- Made of pure cotton

- Intaglio printing

- Tactile marks (on €200 and €500)

- Wire and multi-tone watermark

- Security thread

- See-through register when note is held to the light

- Perforations in the hologram foil

- Hologram foil

- Optically variable ink (€50, €100, €200, and $€ 500$ )

- Iridescent stripe (€5, €10, and $€ 200$ ) 
Figure 4

Euro Currency Area: Security and Accessibility Features

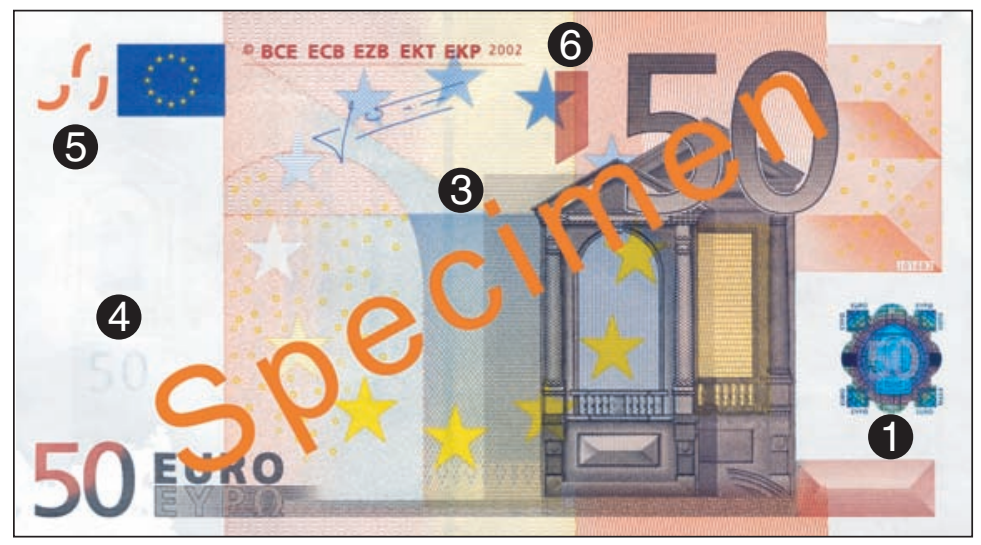

Front

\section{Security Features}

1. Holographic image and perforations

2. Color-changing ink

3. Security thread

4. Watermark

5. Partial images printed on the front and back align to form the value numeral (see-through number)

6. Raised ink (intaglio printing)

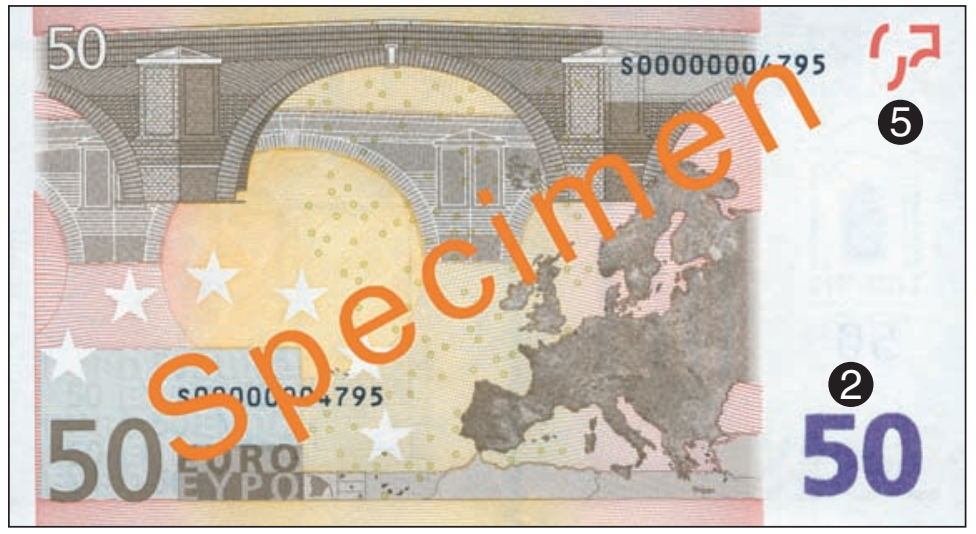

Accessibility Features

- Different sizes: the higher the banknote, the bigger the banknote

- Striking, clearly contrasting colors

- Large numerals

- Intaglio printing

Back
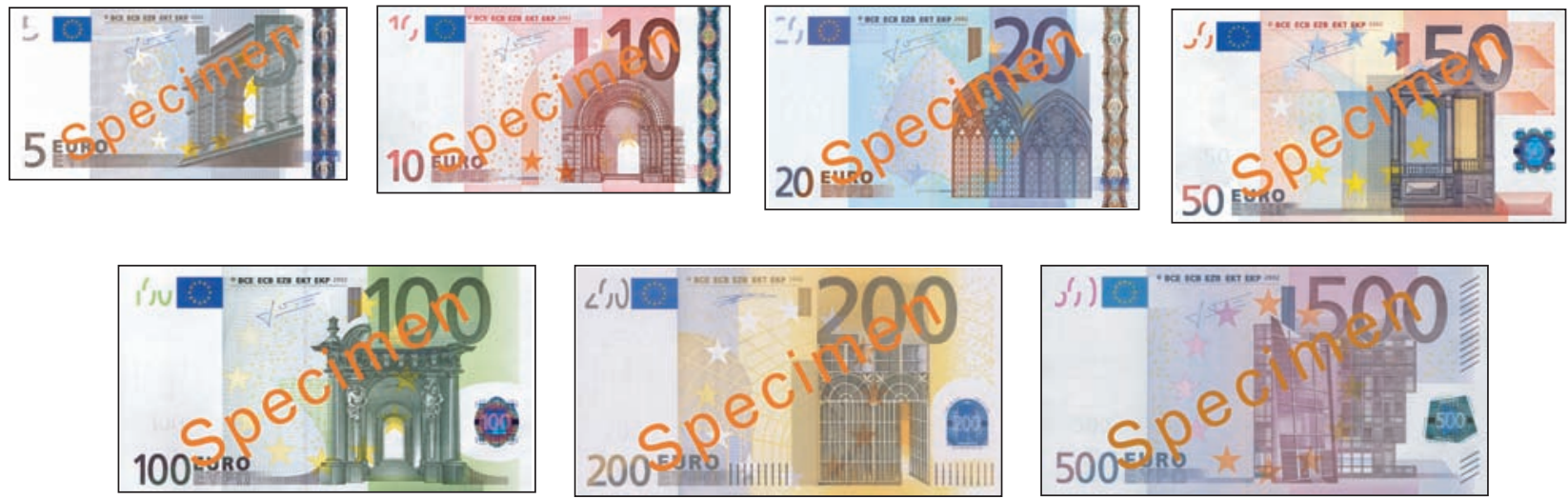

NOTE: See Tables 1 and 2 and the appendix for a complete listing of security and accessibility features. SOURCE: European Central Bank. 
- Mini and microprinting

- Fluorescence, presence of elements only visible under UV light

\section{Accessibility Features}

- Sizes that vary by denomination

- Primary colors that vary by denomination: bold, striking colors/clear, contrasting colors among denominations

- Oversize denomination numerals

- High-relief intaglio printing

- Tactile marks (€200and $€ 500$ only)

\section{Hong Kong (see Figure 5)}

The Hong Kong Monetary Authority has authorized (delegated) the issuance of Hong Kong banknotes (currency name: Hong Kong dollar; currency code: HKD; currency symbol: \$ or HK\$) to three commercial banks-The Hongkong and Shanghai Banking Corporation Ltd., the Standard Chartered Bank, and the Bank of China (Hong Kong) Limited- under specific terms and conditions stipulated by the Hong Kong government. The notes issued by the three banks differ somewhat in design although all banknotes are printed in Hong Kong by Hong Kong Note Printing Limited. ${ }^{47}$ The notes illustrated here are those issued by HongKong and Shanghai Banking Corporation Ltd. (HSBC).

Under normal usage, a banknote is estimated to last for an average of about two years. Production costs are confidential.

In 2003, the Hong Kong Monetary Authority reported that:

"Forgery of banknotes is not a major problem in Hong Kong, thanks to the quality of our existing banknotes and the good work of the police in tracking down counterfeiters. However, constant changes in technology are increasing the vulnerability to counterfeiting and it is thus necessary to keep more than one step ahead of those who might try to exploit any gaps in the security of our banknotes..."48

\footnotetext{
${ }^{47}$ Additional information may be found at www.info.gov.hk/hkma/ new_hk_banknotes/eng/index.htm.

${ }^{48}$ See www.info.gov.hk/hkma/eng/viewpt/20030904e.htm.
}

Although more recently, there has been a problem of counterfeits of the old series (2000 and 2002) Hongkong and Shanghai Banking Corporation $\$ 1,000$ banknotes. ${ }^{49}$

Hong Kong banknotes are made of 100 percent cotton fiber, ${ }^{50}$ which does not fluoresce under UV light. They vary in length and color according to denomination. The HK $\$ 10$ banknote is the smallest (133 $\mathrm{mm}$ by $66 \mathrm{~mm}$ ), and the HK\$1,000 banknote is the largest (163 mm by $81.5 \mathrm{~mm}$ ). Enhanced intaglio printing serves both as a security and accessibility feature.

In the design phase for the currency issued in 2003 and 2004, the Hong Kong Monetary Authority consulted with major advocacy organizations to include accessibility features for the blind and visually impaired. In addition, the three note-issuing banks and the Hong Kong Monetary Authority produce a template to aid the visually impaired in measuring a banknote's size.

\section{Security Features}

- Fluorescent machine-readable barcode

- Iridescent images

- Denomination numeral in optical variable ink

- Holographic windowed thread

- Concealed image/denomination

- Intaglio printing

- Invisible fluorescent fibers

- Watermarks

- Security thread

- See-through feature

- Serial numbers

\section{Accessibility Features}

- Sizes that vary by denomination

- Colors that vary by denomination

- A bold, large denomination numeral on the front of all banknotes at a common

\footnotetext{
${ }^{49}$ See www.info.gov.hk/hkma/eng/press/2007/20070320e3.htm.

50 The HK\$10 polymer banknote is scheduled to be put into circulation gradually starting July 9, 2007. See www.info.gov.hk/hkma/ eng/press/2007/20070615e6.htm and www.info.gov.hk/hkma/ eng/polymer/leaflet_polymer_eng.pdf.
} 


\section{Figure 5}

\section{Hong Kong: Security and Accessibility Features}

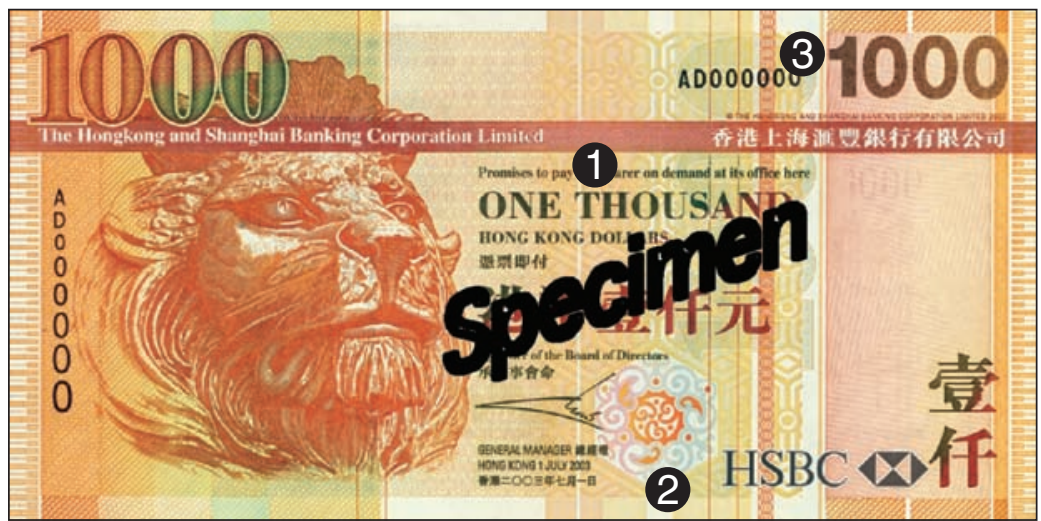

Front

\section{Security Features}

1. Fluorescent machine-readable barcode

2. See-through feature

3. Denomination numeral in optical variable ink

4. Holographic windowed thread

\section{Accessibility Features}

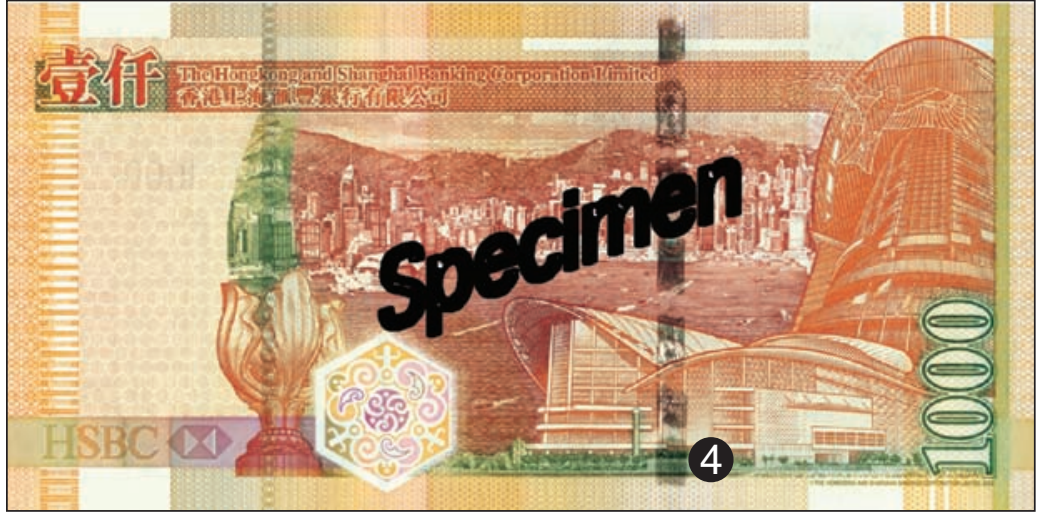

- Different sizes

- Distinctive colors

- Large, bold denomination numerals

- Enhanced intaglio printing

Back
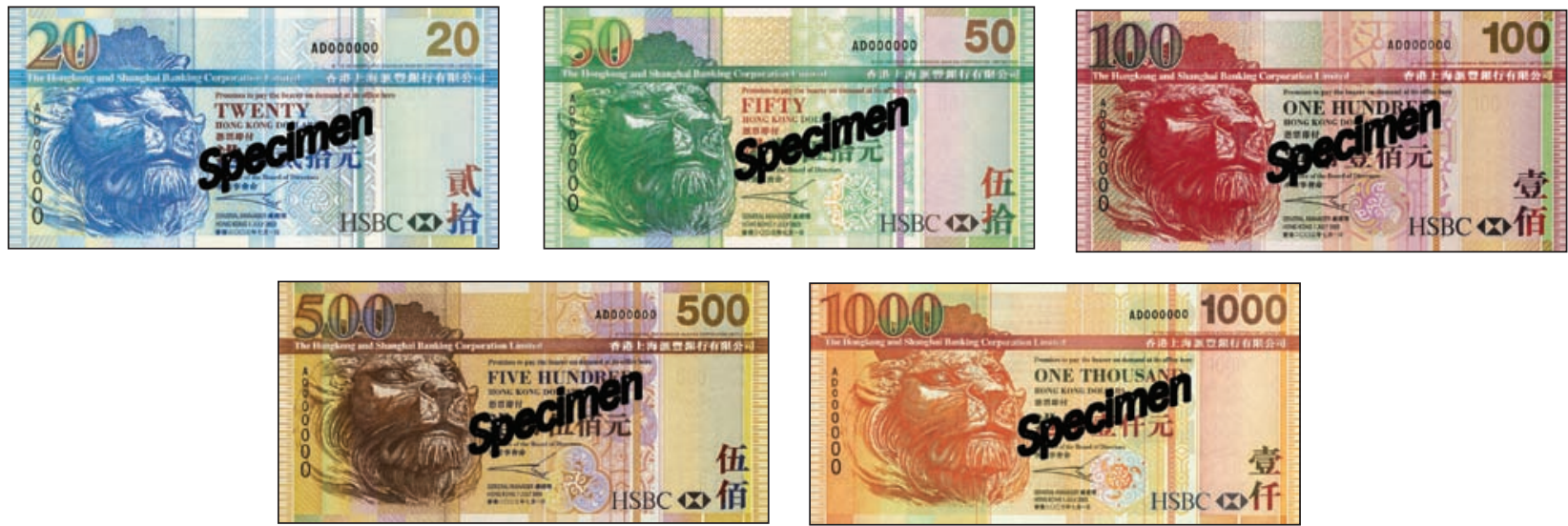

NOTE: See Tables 1 and 2 and the appendix for a complete listing of security and accessibility features.

SOURCE: The Hong Kong and Shanghai Banking Corporation Limited, with permission of the Hong Kong Monetary Authority. 
location, with deep engraving to give a pronounced tactile feel

- A bold denomination numeral in negative outline located at a common location at the back of all banknotes

- Enhanced intaglio printing to give stronger embossing effect

- Banknote size measurement template

\section{Japan (see Figure 6)}

The Bank of Japan is the sole issuer of Japanese banknotes (currency name: yen; currency code: JPY; currency symbol: ¥). The banknotes are manufactured by the National Printing Bureau, an incorporated administrative agency. ${ }^{51}$

In response to the increase of Japanese counterfeit banknotes in recent years, the Bank of Japan issued a new series of banknotes in 2004 with improved security features. There are four denominations: $¥ 1,000, ¥ 2,000$, $¥ 5,000$, and $¥ 10,000$. These redesigned Japanese yen notes vary in width and color according to denomination. The $¥ 1,000$ banknote is the shortest note, measuring $76 \mathrm{~mm}$ wide by $150 \mathrm{~mm}$ long, and the ¥10,000 banknote is the longest, measuring $76 \mathrm{~mm}$ wide by $160 \mathrm{~mm}$ long. Bank of Japan notes contain machine-readable features intended to assist mechanical note processing. So far as we are aware, no consumer-level devices to assist the blind and visually impaired have been developed.

The average durability of the Bank of Japan notes is one to two years for the $¥ 1,000$ and $¥ 5,000$ notes and four to five years for the $¥ 10,000$ notes. ${ }^{52}$

In fiscal year 2005, the total manufacturing cost of 4.08 billion banknotes amounted to $¥ 61.7$ billion, approximately $¥ 15.1$ per banknote.

The current series of Bank of Japan notes contain "tactile marks" created by high-relief intaglio printing to assist the visually impaired. High-relief numerals, created by intaglio printing, both deter counterfeiting and assist the visually impaired. The Bank of Japan occasionally makes

\footnotetext{
${ }^{51}$ Additional information may be found at www.boj.or.jp/en/type/ release/zuiji/kako03/bnnew3.htm.

${ }^{52}$ Source: Bank of Japan.
}

studies to improve the accessibility features for the visually impaired.

\section{Security Features}

- Hologram (¥10,000 note)

- Watermark bar pattern

- Latent image

- Pearl ink

- Ultra-fine-line printing

- Intaglio printing

- Microprinting

- Luminescent ink

\section{Accessibility Features}

- Tactile marks (intaglio printing)

- Sizes that vary by denomination

- Colors that vary by denomination

\section{Singapore (see Figure 7)}

The Monetary Authority of Singapore (MAS) is the sole issuer of banknotes (currency name: dollar; currency code: SGD; currency symbol: \$ or S\$) in Singapore. ${ }^{53}$ In 1990, the MAS issued their first polymer note of $\$ \$ 50$ denomination. Polymer notes are more durable and cost-effective. Both paper and polymer banknotes are currently in circulation. Their "Portrait Series" notes were first issued in 1999. This series has seven denominations. The banknotes vary in length, width, and color according to denomination. The smallest note is the $S \$ 2$ note, measuring $126 \mathrm{~mm}$ in height by $63 \mathrm{~mm}$ in width; the largest note is the S\$10,000 note and measures $180 \mathrm{~mm}$ in length by $90 \mathrm{~mm}$ in height. Singapore banknotes include machine readable features intended to assist currency processing and authentication.

High-relief intaglio printing of several characteristics, including the denomination numeral, serves as an accessibility and anti-counterfeiting feature. During the design phase of the Portraitseries notes, MAS consulted with the Singapore Association of the Visually Handicapped on their needs for the new series of banknotes. The

\footnotetext{
53 Additional information may be found at www.mas.gov.sg/
} masmcm/bin/pt1Singapore_Circulation_Notes.htm. 
Figure 6

Japan: Security and Accessibility Features
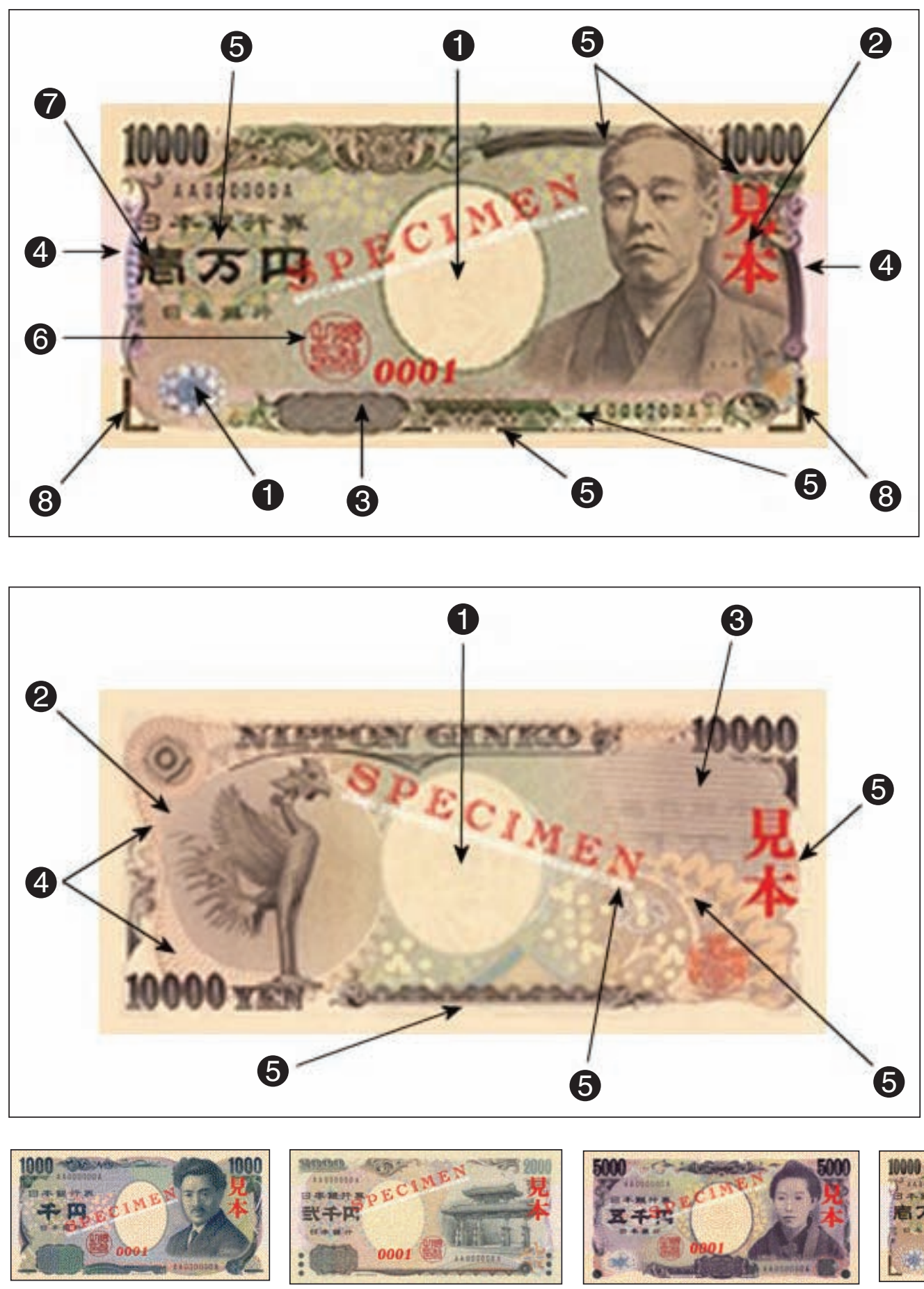

\section{Security Features}

1. Hologram

2. Watermark bar pattern

3. Latent image

4. Pearl ink

5. Microprinting

6. Luminescent ink

7. Intaglio printing

Accessibility Features

8. Intaglio-printed recognition symbol

- Different sizes

- Different colors

NOTE: See Tables 1 and 2 and the appendix for a complete listing of security and accessibility features. SOURCE: Bank of Japan.

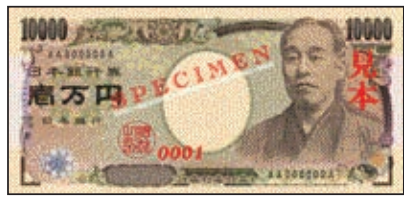

Back 


\section{Figure 7}

\section{Singapore: Security and Accessibility Features}

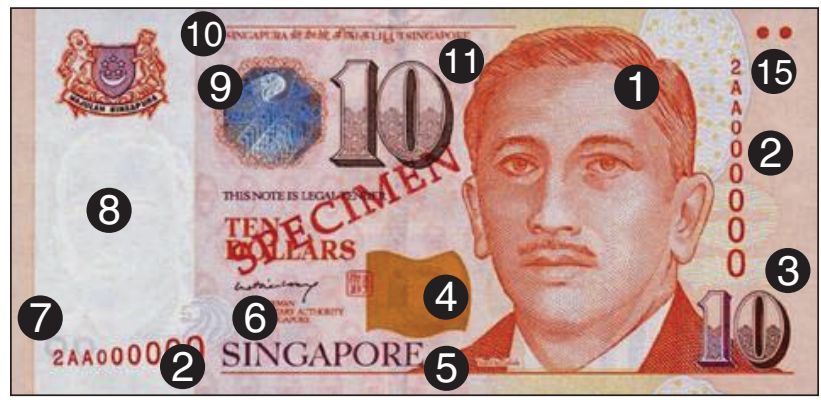

Paper Note

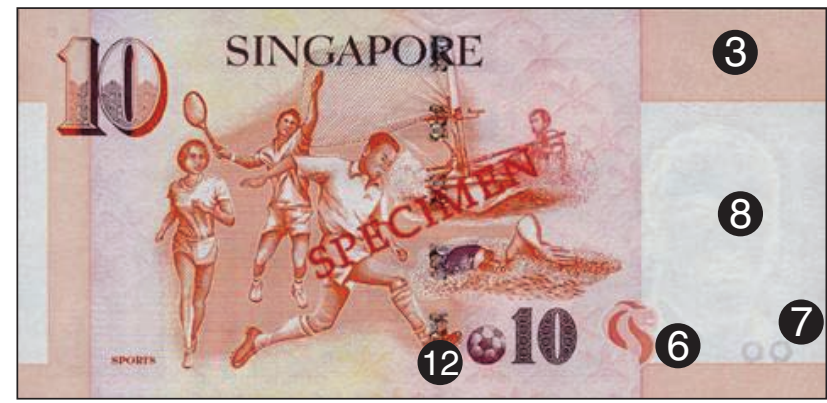

Back
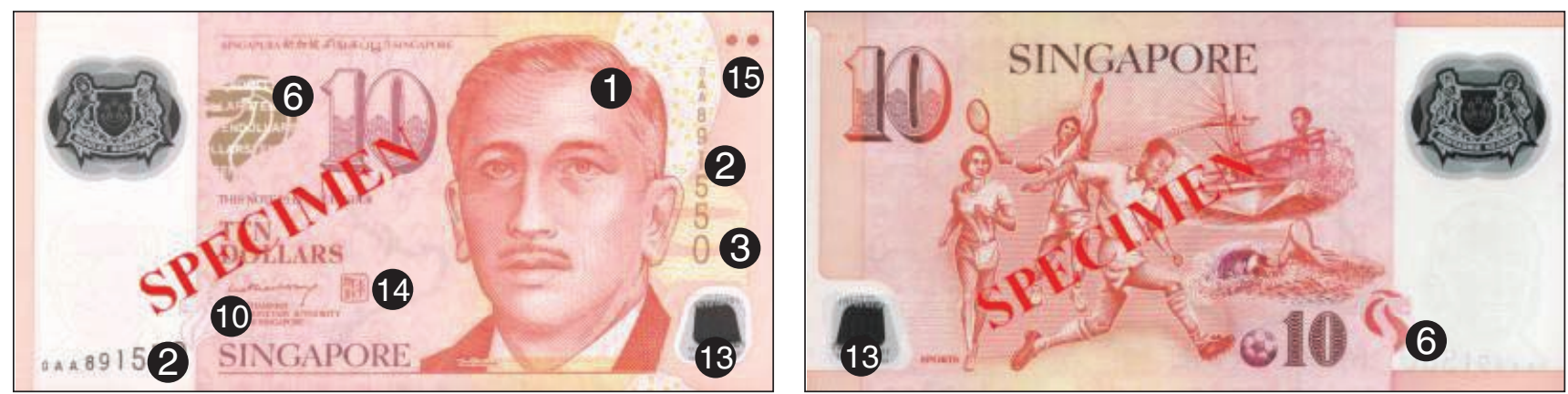

Polymer Note

1. Engraved portrait

2. Asymmetrical serial number

3. Anti-color copying line structures

4. Lift twin

5. Intaglio printing

Security Features

6. Perfect registration

7. Highlight watermark

8. Watermark

9. Kinegram

10. Microprinting
11. Lithographic print

12. Security thread

13. Invisible feature

14. Fluorescent ink

Accessibility Features

15. Braille codes

- Different sizes

- Different colors
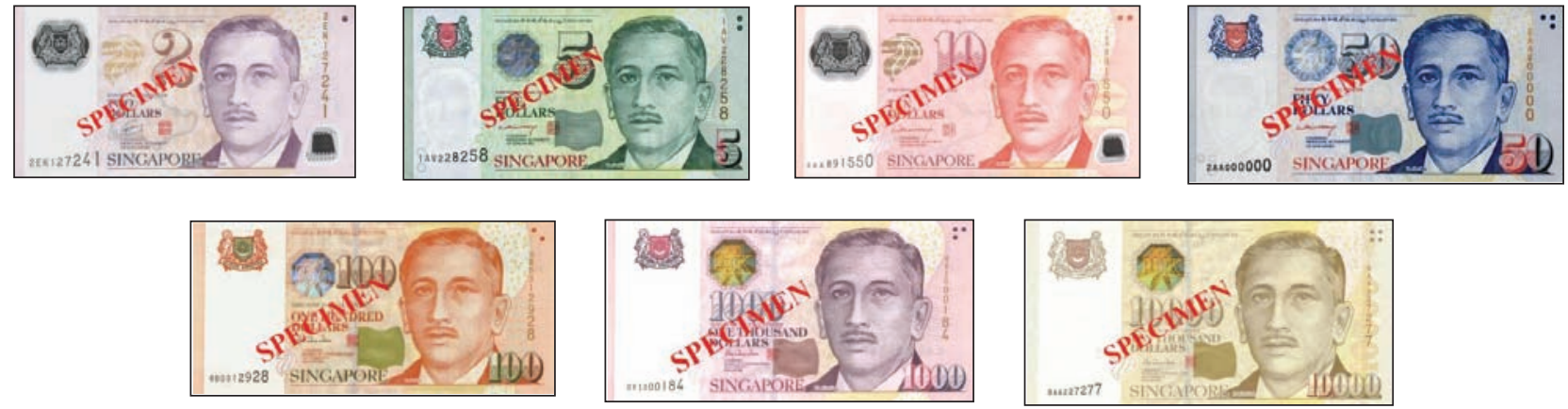

NOTE: See Tables 1 and 2 and the appendix for a complete listing of security and accessibility features. SOURCE: Monetary Authority of Singapore. 
Association recommended the printing of Braille codes and varying note size by denomination. The Braille codes are printed in heavy, high-relief intaglio on the top right of the front of each note.

According to the Monetary Authority of Singapore, the cost and duration of their banknotes by denomination are as follows:

- S\$2 polymer $\mathrm{S} \$ 0.10$ 72-96 months (issued in January 2006, still monitoring the performance)

- S\$5 paper $\quad \mathrm{S} \$ 0.10$ 18-24 months

- $\mathrm{S} \$ 10$ paper $\quad \mathrm{S} \$ 0.09$ 24-36 months

- S\$10 polymer $\mathrm{S} \$ 0.12$ 72-96 months (issued in May 2004, still monitoring the performance)

- $\mathrm{S} \$ 50$ paper $\quad \mathrm{S} \$ 0.08$ 24-36 months

- S\$100 paper $\quad \mathrm{S} \$ 0.07$ 48-60 months

- $S \$ 1,000$ paper $S \$ 0.09$ 48-60 months

- $\mathrm{S} \$ 10,000$ paper $\mathrm{S} \$ 0.55$ 48-60 months

Security Features

- Microprinting

- Kinegram

- Lithographic print

- Engraved portrait

- Braille codes

- Asymmetrical serial numbers (vertical and horizontal)

- Anti-color-copying line structures

- Lift twin

- Intaglio printing

- Highlight watermark

- Watermark

- Perfect registration

- Security thread

- Invisible feature: non-reflective under UV light

- See-through windows on polymer notes

\section{Accessibility Features}

- Braille codes

- Sizes that vary by denomination

- Colors that vary by denomination

- Intaglio printing

\section{Sweden (see Figure 8)}

The Sveriges Riksbank is the sole issuer of Swedish banknotes (currency name: krona; currency code: SEK; currency symbol: kr). ${ }^{54}$ Swedish banknotes are 100 percent cotton. Swedish banknotes are issued in five denominations $(20,50$, 100,500 , and 1,000 kronor) and vary in length, width, and color according to denomination. The 20 kronor banknote is the smallest in size, measuring $67 \mathrm{~mm}$ in width and $120 \mathrm{~mm}$ in length. The 1,000 kronor banknote is the largest, measuring $82 \mathrm{~mm}$ in width and $160 \mathrm{~mm}$ in length. Banknote lifetime varies by denomination, with 20 kronor banknotes being fit for circulation for about one year and 1,000 kronor for about five years. The cost of production is about 7.5 U.S. cents per banknote. Swedish banknotes contain machinereadable features but, so far as we are aware, no handheld devices are available to assist the visually impaired. Intaglio printing of the denomination and portrait serve as both security and accessibility features.

\section{Security Features}

- Watermark

- Security thread

- See-through picture

- Intaglio printing

- Foil strip/hologram

- Fluorescent picture (for banknotes with a foil strip)

- Microlettering

- Shimmering mother-of-pearl ink

- Motion (a moving image in the striped bank image; included in the 1,000 krona note with a foil strip only)

\footnotetext{
${ }^{54}$ Additional information may be found at www.riksbank.com/ templates/SectionStart.aspx?id=10890.
} 


\section{Figure 8}

\section{Sweden: Security and Accessibility Features}

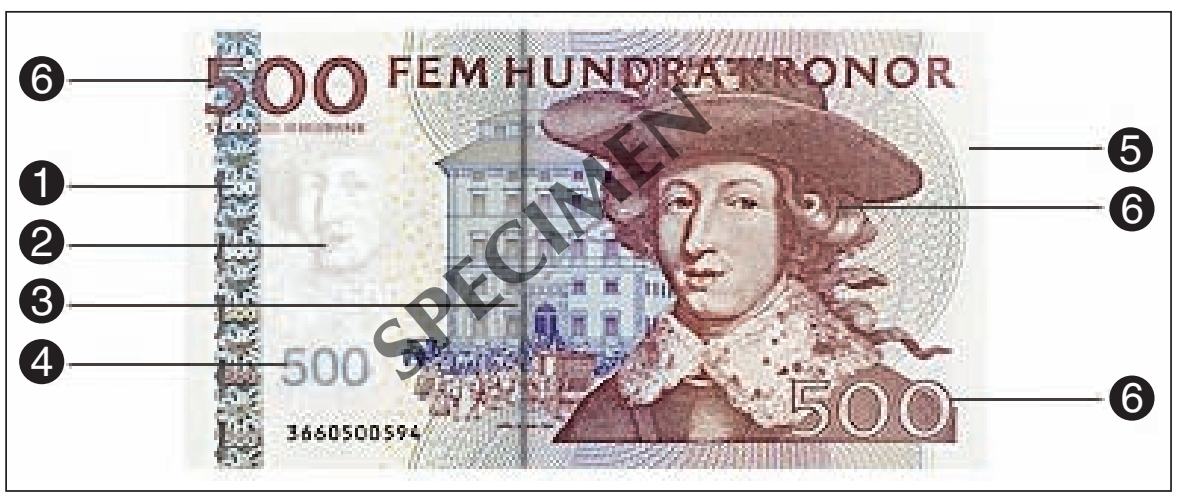

Security Features

1. Foil strip with hologram

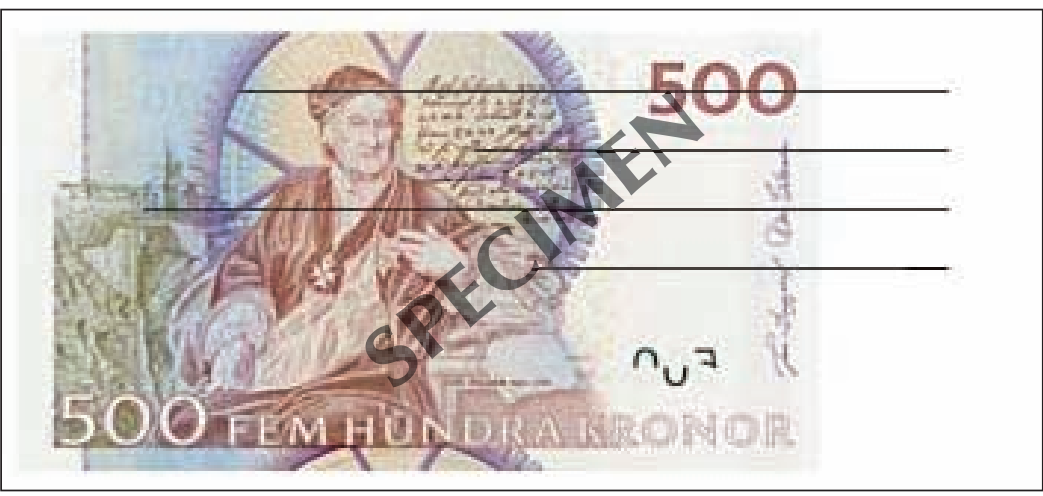

2. Watermark

3. Security thread

4. See-through picture

5. Raw cotton banknote, gives the note a special texture

Accessibility Features

6. Intaglio printing

- Different sizes

- Different colors

Back

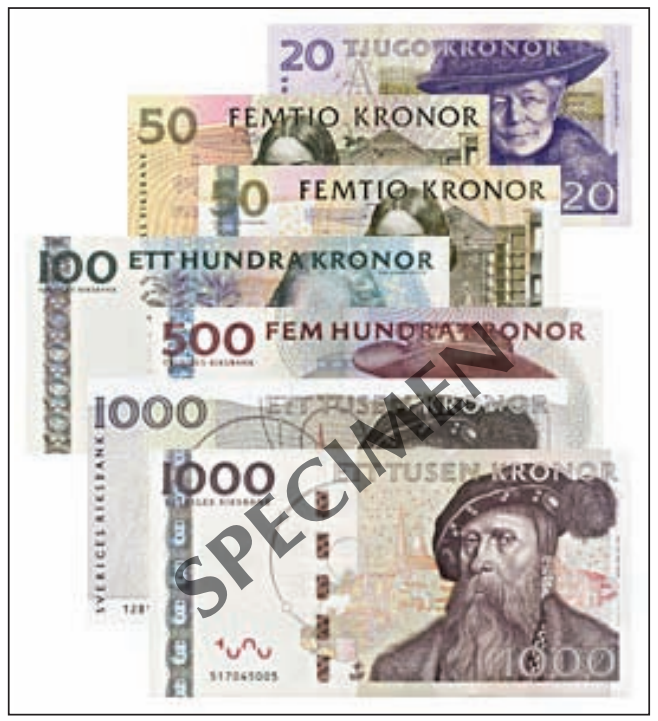

NOTE: See Tables 1 and 2 and the appendix for a complete listing of security and accessibility features. SOURCE: Riksbank. 


\section{Figure 9}

\section{Switzerland: Security and Accessibility Features}

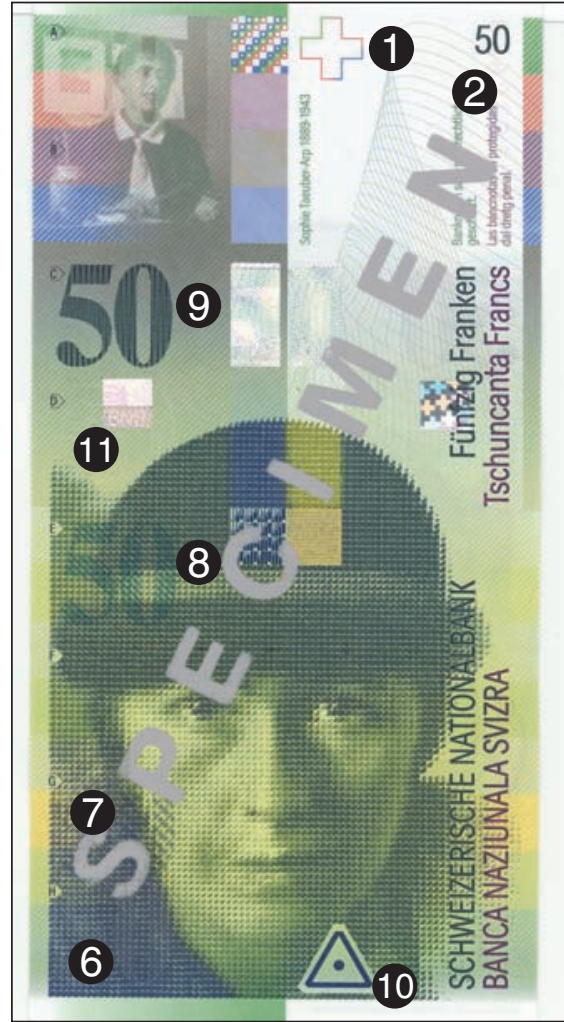

Front

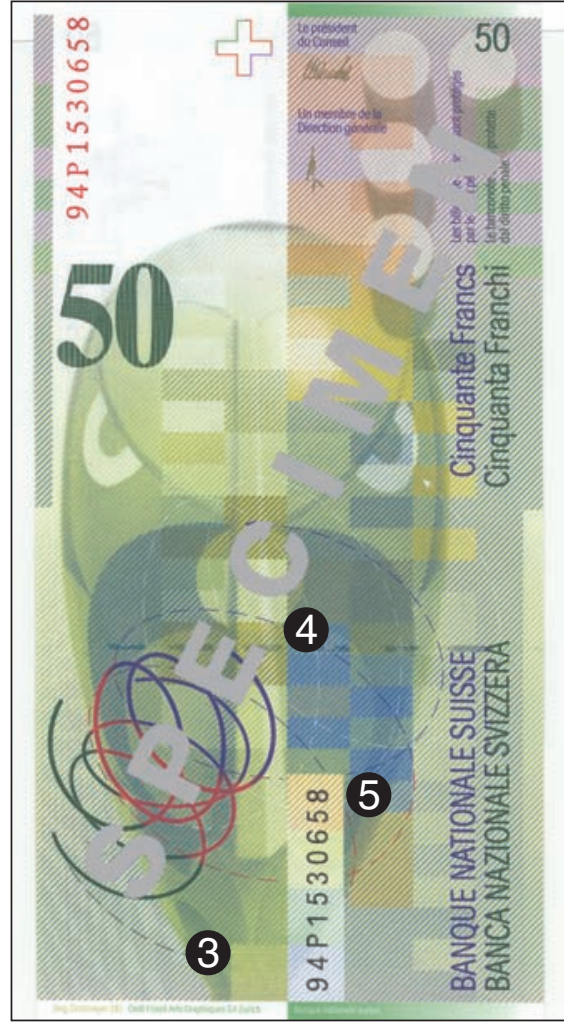

Back

\section{Security Features}

1. Transparent image

2. Fine lines that change colors

3. Microtext

4. Security thread

5. Serial number

6. Tilt effect

7. Metallic digits

8. Optically variable print

9. Intaglio printing

Accessibility Features

10. Recognition symbol

11. Perforated number

- Different sizes

- Different colors
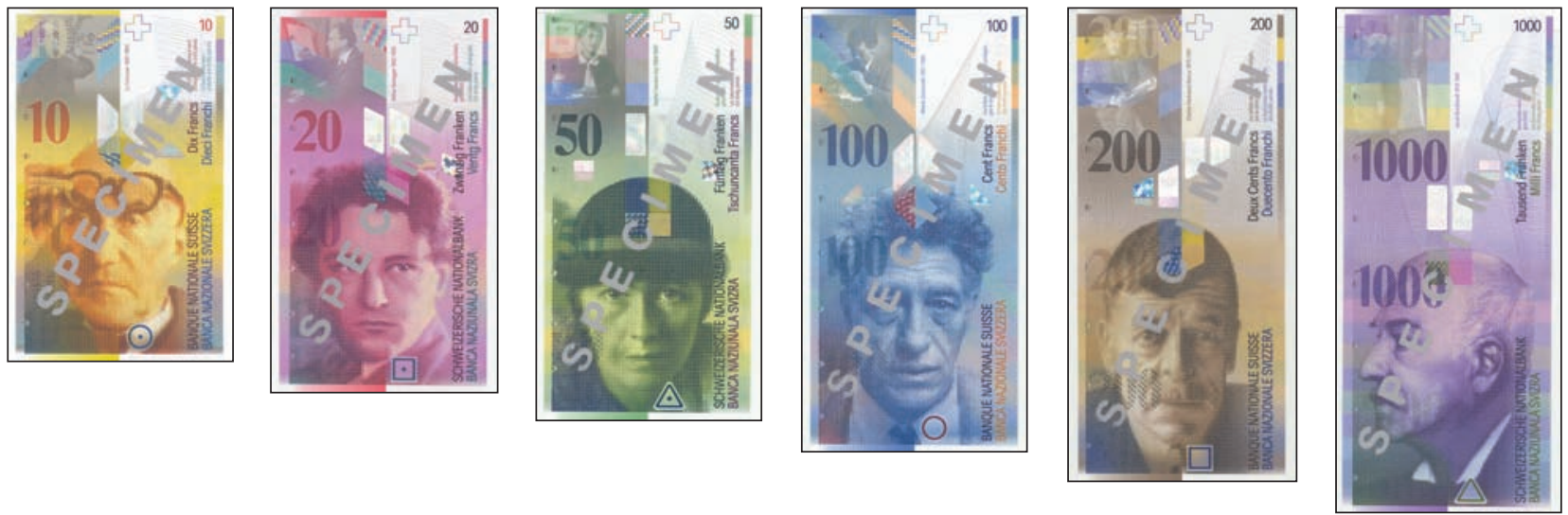

NOTE: See Tables 1 and 2 and the appendix for a complete listing of security and accessibility features. SOURCE: Swiss National Bank. 


\section{Accessibility Features}

- Sizes that vary by denomination

- Colors that vary by denomination

- Intaglio printing

\section{Switzerland (see Figure 9)}

The Swiss National Bank's (SNB) network of cash distribution services is the issuing and redeeming authority of Swiss banknotes (currency name: Franc; currency code: CHF; currency symbol: CHF, Fr). ${ }^{55}$ The network includes the SNB's three bank offices, 16 agencies, and 234 domestic correspondents. Swiss franc notes are printed on paper made of linters and short cotton fibers. Swiss franc banknotes vary in length and color according to denomination. There are six denominations (10, 20, 50, 100, 200, and 1000 francs). All notes measure $74 \mathrm{~mm}$ in width. The length varies by denomination, in $11 \mathrm{~mm}$ increments, with the 10 franc banknote being the shortest $(126 \mathrm{~mm})$ and the 1000 franc being the largest $(181 \mathrm{~mm})$. Some of the security elements in Swiss banknotes are machine readable.

The cost of producing Swiss franc banknotes is approximately 30 centimes per new note. The average duration of the banknotes is as follows:

- 10 CHF: 2 years

- $20 \mathrm{CHF}: 1.5$ years

- $50 \mathrm{CHF}: 1.5$ years

- 100 CHF: 3.5 years

- 200 CHF: 3 years

- 1000 CHF: 10 years

Perforated numerals serve as both an accessibility and security feature. A tactile symbol varying by denomination is embossed at the lower end of each note as an additional accessibility feature.

\section{Security Features}

- Transparent register

- Watermark digits

- Intaglio printing (digits)

- Perforated number

\footnotetext{
${ }^{55}$ Additional information may be found at www.snb.ch/en/iabout/cash.
}

- Optically variable ink

- UV digits

- Metallic digits

- Tilt effect

\section{Accessibility Features}

- Sizes that vary by denomination

- Colors that vary by denomination

- Perforated number

- Intaglio printing (digits)

\section{United Kingdom (see Figure 10)}

The Bank of England is the sole issuer of banknotes (currency name: pound; currency code: GBP; currency symbol: $£$ ) in the United Kingdom. ${ }^{56}$ Bank of England banknotes are produced by De La Rue Currency and made from cotton fiber and linen rag. The banknotes vary by color, length, and width according to denomination, with the $£ 5$ note measuring $135 \mathrm{~mm}$ by $70 \mathrm{~mm}$ and the $£ 50$ note measuring $156 \mathrm{~mm}$ by $85 \mathrm{~mm}$.

The Bank of England estimates an average life of banknotes of about 1 year for the $£ 5$ note to five or more years for the $£ 50$ note.

During the banknote design phase, advice from the Royal National Institute of the Blind, a U.K. charity, is sought and their recommendations are implemented. For the new $£ 20$ series F note, for example, the Royal National Institute of the Blind recommended that large-high contrast numerals be included and the size and color differential between denominations be retained; both were accepted by the Bank of England. In addition, a recognition symbol unique to each denomination is included on the front of the banknote to aid the visually impaired.

\section{Security Features}

- Made of cotton and linen paper

- Metallic thread

- Watermark

- Print quality

\footnotetext{
${ }^{56}$ Additional information may be found at www.bankofengland.co.uk/ banknotes/current/index.htm.
} 
Figure 10

United Kingdom: Security and Accessibility Features

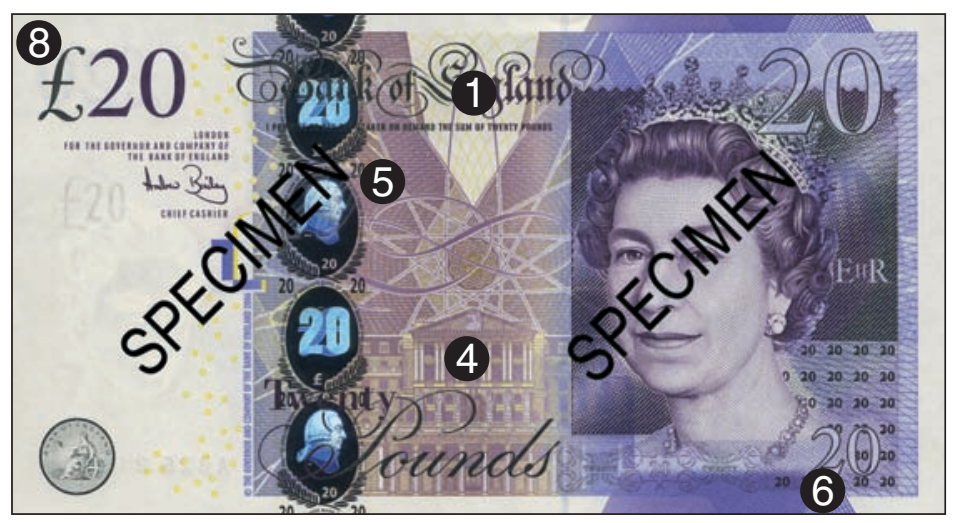

Front

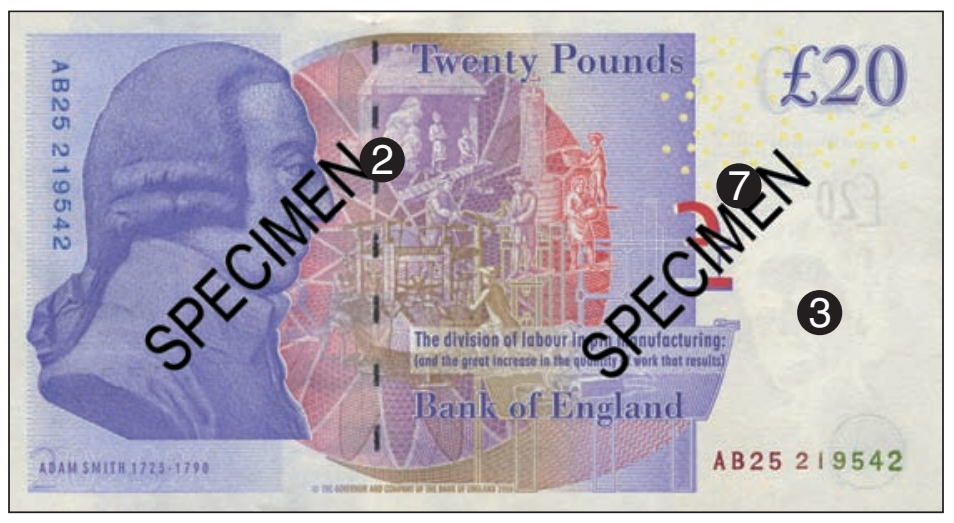

Security Features

1. Intaglio printing

2. Metallic thread

3. Watermark

4. Print quality

5. Holographic strip

6. Microlettering

7. See-through register

Accessibility Features

8. Large denomination numerals

- Different sizes

- Different colors
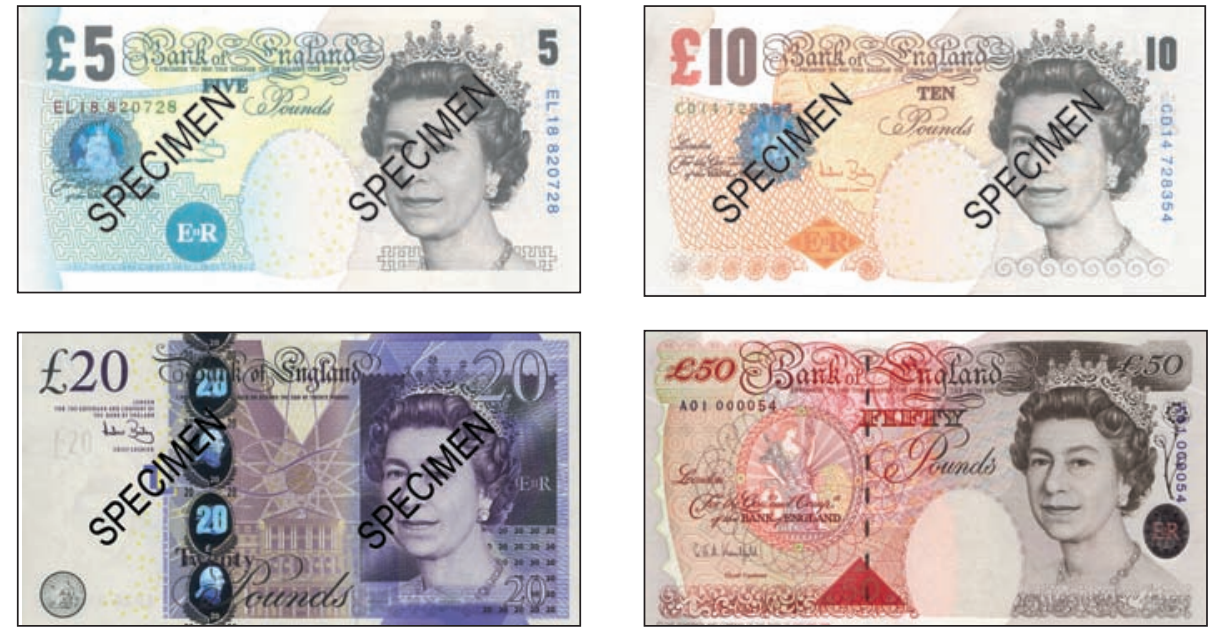

NOTE: See Tables 1 and 2 and the appendix for a complete listing of security and accessibility features. SOURCE: Bank of England. 
- Hologram

- UV light

- Microlettering

- Foil (on $£ 50$ note)

\section{Accessibility Features}

- Sizes that vary by denomination

- Colors that vary by denomination

- Large denomination numerals

- Densely colored recognition symbols to indicate denomination:

- $£ 5$ : turquoise circle

- $£ 10$ : orange diamond

- $£ 20:$ purple square

- £50: red triangle

\section{United States (see Figure 11)}

The United States government is the sole issuer of U.S. banknotes (currency name: dollar; currency code: USD; currency symbol: \$). ${ }^{57}$ The BEP, a part of the U.S. Treasury Department, produces U.S. banknotes, which are placed into circulation by the Federal Reserve Banks. Banknotes are made of paper composed of 25 percent linen and 75 percent cotton, with red and blue synthetic fibers distributed evenly throughout the paper. U.S. banknotes do not vary by size or primary color across denominations; they measure 2.61 inches wide by 6.14 inches long and 0.0043 inches thick (or $66.3 \mathrm{~mm}$ wide $\times 155.96 \mathrm{~mm}$ long and $0.11 \mathrm{~mm}$ thick). There are seven denominations of U.S. banknotes ( $\$ 1, \$ 2, \$ 5, \$ 10, \$ 20, \$ 50$, and $\$ 100)$. The $\$ 100$ note has been the largest denomination issued since 1969. The $\$ 2$ banknote circulates in small numbers.

The estimated cost of producing U.S. banknotes was 5.6 cents per banknote during fiscal year $2006^{58}$. The estimated average life of a U.S. banknote varies by denomination:

\footnotetext{
${ }^{57}$ The BEP prints all banknotes, based on production orders sent by the Federal Reserve Banks, and ships the notes to the Federal Reserve: at this point, they are just paper. The notes are placed into circulation by the Federal Reserve Banks, which means the Fed ships them from their vaults to a non-Fed location. Additional information may be found at www.moneyfactory.gov/.

${ }^{58}$ www.federalreserve.gov/generalinfo/foia/2007newcurrency.htm.
}

- \$1: 21 months

- \$5: 16 months

- \$10: 18 months

- \$20: 24 months

- \$50: 55 months

- \$100: 89 months

The U.S. government introduced the "New Currency Design” U.S. banknotes in 1996. This was the first major redesign of U.S. banknotes since 1928. Sophisticated security features were added to deter counterfeiting domestically as well as abroad. Security features include colorshifting ink, watermarks, and security threads. In 2003, The "New Color of Money" banknotes were introduced. These banknotes feature different subtle background colors for different denominations to assist the visually impaired. A larger numeral in the lower right corner on the back of the notes was included as an additional accessibility feature. All new Federal Reserve notes issued since 1997 include machine-readable features (such as infrared markings) that might be used by handheld currency readers for the visually impaired. To date, few such readers have been introduced and some users have reported difficulty using them with newer design banknotes (see footnote 25).

\section{Security Features}

- Watermark

- Color-shifting inks

- Fine-line printing patterns (intaglio printing on both the face and back)

- Enlarged off-center portraits

- Low-vision feature

- Machine-readable feature

- Security thread

- Microprinting

\section{Accessibility Features}

- Larger denomination numeral on reverse

- Large portraits

- Subtle color patterns on face and back (Series 2004) 


\section{DETAIL OF SELECT SECURITY FEATURES FOR THE \$50 U.S. BANKNOTE}

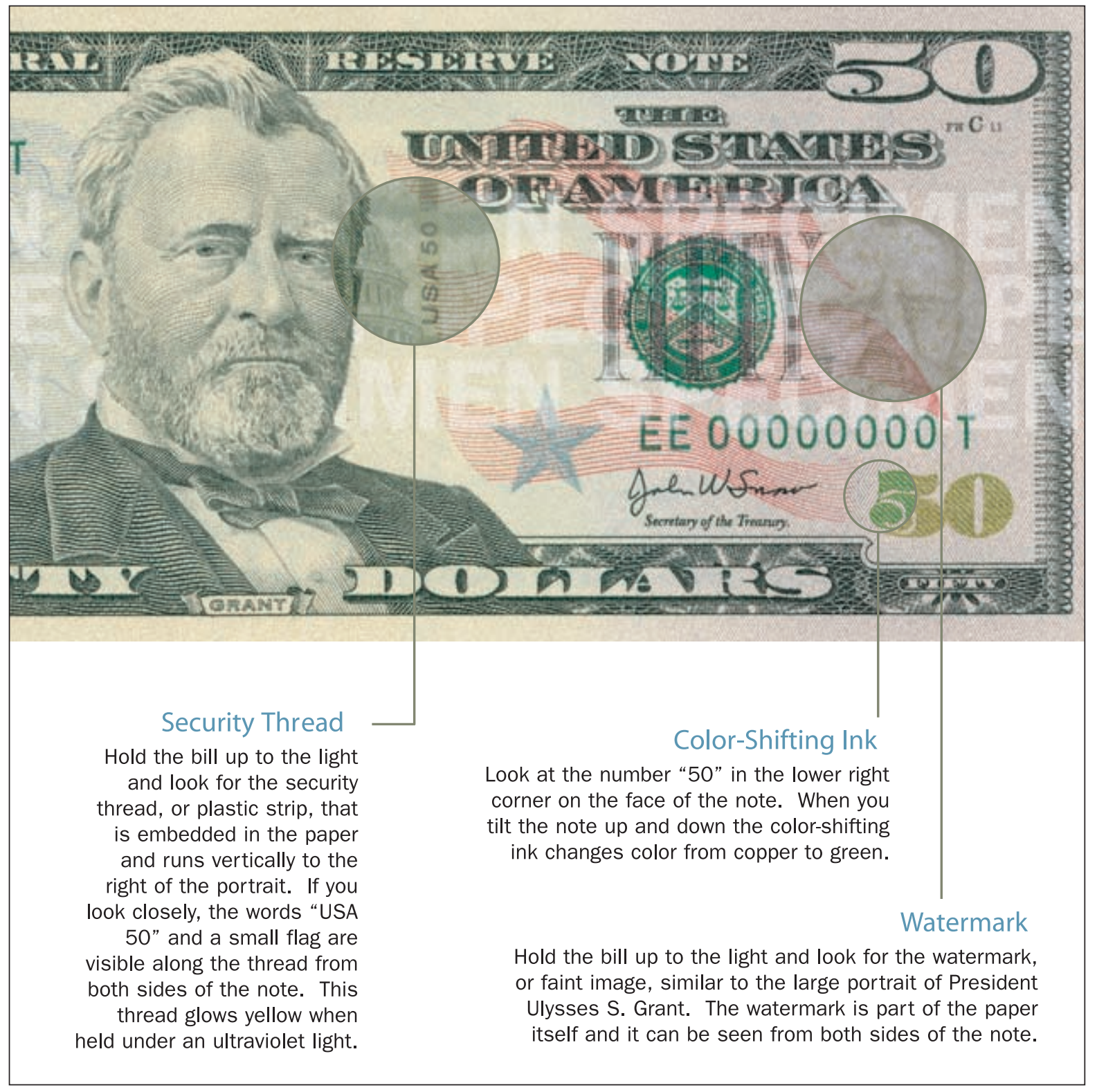

NOTE: The above insert is a partial reproduction of an image from the web site of the U.S. Bureau of Engraving and Printing. The site provides numerous images, information, and tutorials on the characteristics of U.S banknotes: www.moneyfactory.gov/newmoney/files/Sec_Features_50.pdf. 


\section{Figure 11}

\section{United States: Security and Accessibility Features}

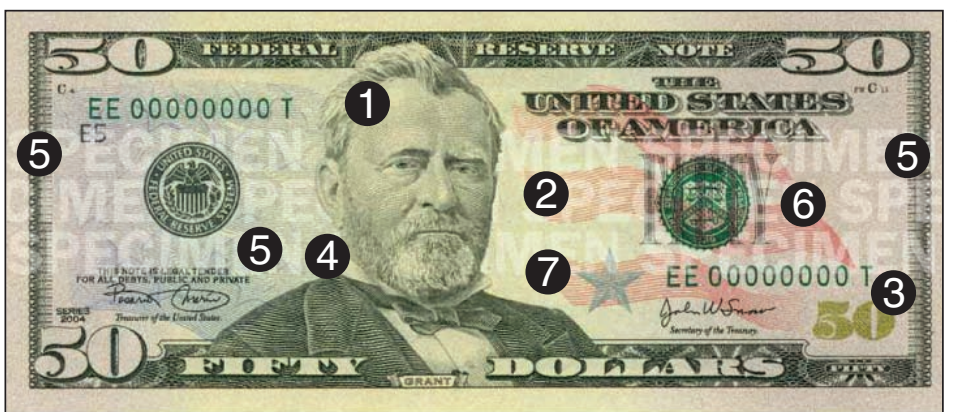

Front

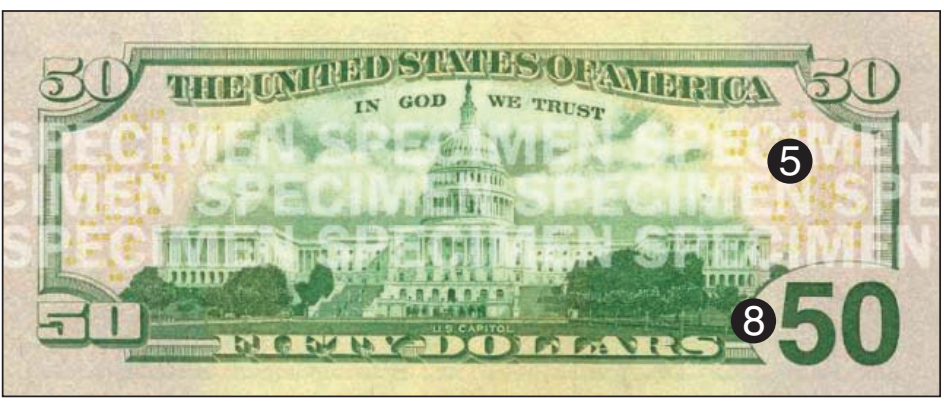

Back
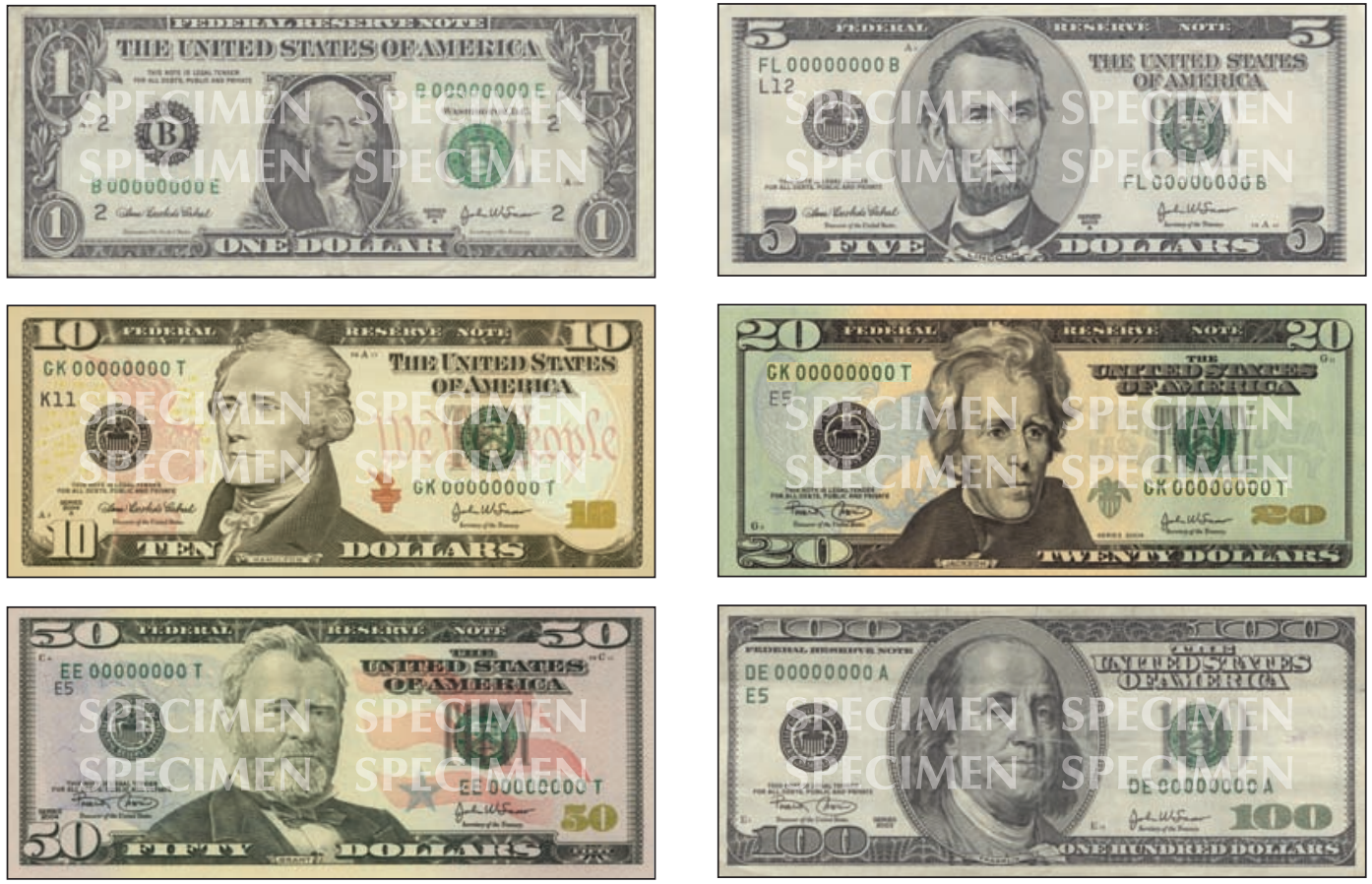

NOTE: See Tables 1 and 2 and the appendix for a complete listing of security and accessibility features.

SOURCE: U.S. Bureau of Engraving and Printing. 


\section{SUMMARY AND CONCLUSIONS}

Currency is widely used in the payment systems of all countries. In each system, there are a large number of participants-households, retail merchants, vending machine firms, financial institutions, high-volume currency processors, and the central bank or currency-issuing authority. The objectives of these stakeholders need not necessarily coincide, and some difficulties in settling on an acceptable currency design for the nation is to be anticipated.

In this analysis, we have focused on currency design features that enhance counterfeit deterrence and improve accessibility for the visually impaired. All currencies issued worldwide contain some of these design features but, interestingly, different countries have made different choices. Among banknotes worldwide, only U.S. notes are widely held outside their country of issue. These foreign holdings benefit the United States when interpreted as a type of non-interestbearing U.S. government debt, and simultaneously benefit foreign holders by providing a stable store of value and medium of exchange in often unstable countries. As a result, the effectiveness of U.S. banknotes' counterfeit deterrence features is a matter of concern worldwide.

All banknotes contain features to deter counterfeiting. Some features, including paper or polymer substrate and intaglio printing, assist the public to readily authenticate notes by touch; indeed, it is widely reported that counterfeit notes are most often detected by the public and bank tellers because "they don't feel right." For authentication, these tactile features are valuable both to normally sighted and visually impaired users. Other note features, including microprinting, magnetic inks, color-varying fluorescent threads, and infrared components, are valuable for machine authentication across a wide range of devices, from handheld devices and vending machines to high-speed currency sorters. Recently published analyses argue that continuing advances in printing technology will require banknote designers to work aggressively to remain ahead of sophisticated counterfeiters.
All banknotes also contain features to assist the visually impaired. Published studies have concluded that the single feature of greatest value for the visually impaired in denominating notes is note sizes that vary by denomination. More than 180 countries in the world issue banknotes. Only two major currency-issuing authorities issue notes that do not vary in size by denominationCanada and the United States. Some nation's have selected designs in which bright primary colors vary by denomination-Canadian and euro notes, for example-while in others, such as the Series-2004 U.S. banknotes and Bank of Japan notes, subtle background colors vary by denomination. Most current note designs include larger denomination numerals than previous designsCanadian and euro notes feature perhaps the most prominent numerals. Series-2004 Federal Reserve notes feature an enlarged denomination numeral on the reverse, albeit smaller than the Canadian or euro note numerals.

The goal of our analysis has been to increase public awareness of the variety, and the trade-offs, among currency design features worldwide. We will have been successful if each reader appreciates a bit more the banknotes they use every day.

\section{REFERENCES}

Andrews, Edmund L. "U.S. Currency Discriminates Against the Blind, Judge Rules," The New York Times, November 29, 2006.

Bank for International Settlements. "General Guidance for National Payment System Development." Committee on Payment and Settlement Systems, January 2006.

Board of Governors of the Federal Reserve System. Ninety-Second Annual Report, 2005. Washington, DC, 2006a.

Board of Governors of the Federal Reserve System. 2007 New Currency Budget. Washington, DC, December 2006b; www.federalreserve.gov/ generalinfo/foia/2007newcurrency.htm.

Bureau of Engraving and Printing. A Study of Mechanisms for the Denomination of U.S. Currency 
by the Blind or Visually Impaired. Report to Congressman Edward R. Roybal, Chairman, U.S. House of Representatives Select Committee on Aging, 1983; fraser.stlouisfed.org/historicaldocs/ tresbep/download/30353/study_of_mechanisms.pdf.

Bureau of Engraving and Printing. "U.S. Unveils New $\$ 50$ Note with Background Colors.” April 28, 2004; www.moneyfactory.gov/newmoney/ main.cfm/media/releases04262004.

Coventry, Les. "Polymer Notes and the Meaning of Life." Presented at the international currency conference, on behalf of the Reserve Bank of Australia, Barcelona, Spain, April 2001; www.rba.gov.au/CurrencyNotes/ConferencePapers/ cu_coventry_0401.html and www.currencyconference.com.

de Heij, Hans A.M. "Public Feedback for Better Banknote Design." Proceedings on behalf of De Nederlandsche Bank NV at IS\&T/SPIE's 18th Annual Symposium on Electronic Imaging; Conference No. 6075, Optical Security and Counterfeit Deterrence Techniques VI, San Jose, CA, January 18, 2006; version 2 dated February 1, 2006; www.dnb.nl/ $\mathrm{dnb} /$ home/file/Public\% 20feed \% 20back $\%$ 20for $\% 20$ better\%20banknote\% 20design_tcm46-145677.pdf.

de Heij, Hans A.M.; DiNunzio, Lisa A. and Strube, Olivier. "Comparence EUR-USD Banknotes: Public's Appreciation and Knowledge." Presented on behalf of De Nederlandsche Bank NV to the Banknote 2003 conference, Washington, DC, February 2-5, 2003; www.dnb.nl/dnb/home/file/ Comparence\% 20EURxUSD\%20banknotes\% 20Banknote\%202003_tcm46-145670.pdf.

European Central Bank. Annual Report, 2005. April 2006a; www.ecb.int/pub/annual/html/index.en.html.

European Central Bank. Biannual Information on Euro Banknote Counterfeiting. Press release, July 13, 2006b; accessed July 2, 2007 at www.ecb.int/press/ $\mathrm{pr} /$ date/2006/html/pr060713.en.html.

European Central Bank. "How the Euro Became Our Money: A Short History of the Euro Banknotes and Coins.” 2007; www.ecb.int/pub/pdf/other/ euro_became_our_moneyen.pdf.
Europol. An Overview of Forgery of Money. January 2006a; www.europol.europa.eu/publications/ SeriousCrimeOverviews/2005/sc6.pdf.

Europol. EU Organized Crime Threat Assessment 2006, 2006b; www.europol.europa.eu/publications/ OCTA/OCTA2006.pdf.

Lambert, Michael J. and Staton, Kristin D. "Opportunities and Challenges of the U.S. Dollar as an Increasingly Global Currency: A Federal Reserve Perspective." Federal Reserve Bulletin, September 2001; www.federalreserve.gov/pubs/ bulletin/2001/0901lead.pdf.

Lang, Brian. "Effectiveness of Public Security and Features on Bank Notes." Speech to Interpol, Tenth International Conference on Currency Counterfeiting, Reserve Bank of New Zealand, April 2002; www.rbnz.govt.nz/speeches/0116878.html.

Mihm, Stephen. "No Ordinary Counterfeit." New York Times Magazine, July 23, 2006.

National Eye Institute. "More Americans Facing Blindness Than Ever Before. Report Released on One of the Most-Feared Disabilities." March 20, 2002; www.nei.nih.gov/news/pressreleases/ 032002.asp.

National Research Council. Counterfeit Deterrent Features for the Next-Generation Currency Design. Committee on Next-Generation Currency Design and Commission on Engineering and Technical Systems. Washington, DC: National Academy Press of the National Academy of Sciences, 1993.

National Research Council. Currency Features for Visually Impaired People. Committee on Currency Features Usable by the Visually Impaired. Washington, DC: National Academy Press of the National Academy of Sciences, 1995.

National Research Council. Is It Real? Identification and Assessment of the Counterfeiting Threat for U.S. Banknotes. Committee on Technologies to Deter Currency Counterfeiting. Washington, DC: National Academy Press of the National Academy of Sciences, 2006. 
National Research Council. A Path to the Next Generation of U.S. Banknotes: Keeping Them Real. Committee on Technologies to Deter Currency Counterfeiting. Washington, DC: National Academy Press of the National Academy of Sciences, 2007.

United States Treasury Department. The Use and Counterfeiting of United States Currency Abroad. Washington, DC: U.S. Government Printing Office, January 2000.

United States Treasury Department. The Use and Counterfeiting of United States Currency Abroad, Part 2. Washington, DC: U.S. Government Printing Office, March 2003.

United States Treasury Department. Treasury Bulletin. Washington, DC: U.S. Government Printing Office, March 2006a.

United States Treasury Department. The Use and Counterfeiting of United States Currency Abroad, Part 3. Washington, DC: U.S. Government Printing Office, September 2006b.
United States Treasury Department. U.S. Department of the Treasury FY 2008 Budget in Brief.

Washington, DC: U.S. Government Printing Office, 2007; www.treas.gov/offices/management/budget/ budgetinbrief/fy2008/bib.pdf.

Van Renesse, Rudolf L. Optical Document Security. Third Edition. Boston: Artech House Publishers, 2005.

Vitale, Susan; Cotch, Mary Frances and Sperduto, Robert P. "Prevalence of Visual Impairment in the United States." Journal of the American Medical Association, May 10, 2006, 295(18), pp. 2158-63.

Volcker, Paul A. Statement before the Subcommittee on Domestic Monetary Policy of the Committee on Banking, Finance and Urban Affairs, U.S. House of Representatives, January 29, 1986;

fraser.stlouisfed.org/historicaldocs/pav/download/ 28190/Volcker_19860129.pdf.

\section{APPENDIX}

\section{Web Sites for Data on Currency Features, Counterfeit Activity, and Numbers of Notes in Circulation}

\section{Australia}

\section{Currency features:}

Currency Features:www.rba.gov.au/CurrencyNotes/SecurityFeaturesAndCounterfeitDetection/ security_features_on_australias_notes.htmlwww.rba.gov.au/CurrencyNotes/vision_impaired.html

\section{Counterfeit volume:}

www.rba.gov.au/PublicationsAndResearch/RBAAnnualReports/2005/Html/bus_serv.html www.rba.gov.au/PublicationsAndResearch/RBAAnnualReports/2006/Html/bus_serv.html

\section{Notes in circulation:}

www.rba.gov.au/CurrencyNotes/Statistics/notes_on_issue.html

\section{Canada}

Currency features:

www.bankofcanada.ca/en/banknotes/counterfeit/security_features.htmlwww.bankofcanada.ca/ en/banknotes/accessibility.html 
Counterfeit volume

www.rcmp.ca/factsheets/fact_counterfeit_e.htm

www.rcmp.ca/scams/counter_e.htm

Notes in circulation:

www.bankofcanada.ca/en/annual/2006/annualreport_2006.pdf

\section{Euro Currency Area}

Currency features:

www.ecb.int/bc/euro/banknotes/security/html/index.en.htmlwww.ecb.int/bc/euro/banknotes/ visually/html/index.en.html

Counterfeit volume:

www.ecb.int/press/pr/date/2007/html/pr070112.en.html

Notes in circulation:

www.ecb.int/bc/faqbc/figures/shared/number_of_banknotes_circulation_pdf_web.pdf?

\section{Hong Kong}

Currency features:

www.info.gov.hk/hkma/new_hk_banknotes/eng/index.htmwww.info.gov.hk/hkma/eng/viewpt/ 20030904e.htm

Counterfeit volume:

Not available

Some discussion on counterfeiting:

www.info.gov.hk/hkma/eng/press/2007/20070320e3.htm

Notes in circulation:

www.info.gov.hk/hkma/eng/statistics/msb/new_msb_tables_b.htm\#money

www.info.gov.hk/hkma/ar2005/english/economic/economic06.htm

\section{Japan}

Currency features:

www.boj.or.jp/en/type/release/zuiji/kako03/bnnew3.htm

Counterfeit volume:

www.boj.or.jp/en/type/release/teiki/ar/data/ar0605.pdf

Notes in circulation:

www.boj.or.jp/en/type/stat/dlong/fin_stat/money/cdab0010.csv

\section{Singapore}

Currency features:

www.mas.gov.sg/currency/currency_info/The_Singapore_Currency.html

www.mas.gov.sg/resource/currency/currency_info/Brochure\%20on\%20\$2\%20Polymer\%20Note.pdf

Counterfeit volume:

Not available

Some discussion on counterfeiting:

www.mas.gov.sg/news_room/letters_to_editors/2007/No_reason_for_retailers_not_to_accept_ 100dollars.html

Notes in circulation:

www.mas.gov.sg/currency/currency_stat/Currency_in_Circulation_Notes.html 


\section{Sweden}

Currency features:

www.riksbank.com/templates/SectionStart.aspx?id=10890

www.riksbank.com/upload/Dokument_riksbank/Kat_publicerat/Broschyrer/banknotes_coins_ 060925.pdf

www.riksbank.com/templates/Page.aspx?id=23941

Counterfeit volume:

www.riksbank.com/upload/Dokument_riksbank/Kat_publicerat/Rapporter/2007/

arsred_popvers_06_eng.pdf

Notes in circulation:

www.riksbank.com/upload/Dokument_riksbank/Kat_publicerat/Rapporter/2007/

arsred_popvers_06_eng.pdf

\section{Switzerland}

Currency features:

www.snb.ch/en/iabout/cash/current/design/id/cash_current_design_principle

www.snb.ch/en/iabout/cash/current/id/cash_security

Counterfeit volume:

www.snb.ch/ext/link?url=\%2fen $\% 2 \mathrm{fmmr} \% 2$ freference $\% 2$ fannrep_2004_accrep $\% 2$ fsource www.snb.ch/ext/link?url=\%2fen $\% 2 \mathrm{fmmr} \% 2$ freference $\% 2$ fannrep_2005_accrep $\% 2$ fsource www.snb.ch/ext/link?url=\%2fen $\% 2 \mathrm{fmmr} \% 2$ freference $\% 2$ fannrep_2006_komplett $\% 2$ fsource

Notes in circulation: www.snb.ch/ext/link?url=\%2fen $\% 2 \mathrm{fmmr} \% 2$ freference $\% 2$ fannrep_2006_rechenschaft $\% 2$ fsource www.snb.ch/ext/link?url=\%2fen $\% 2 \mathrm{fmmr} \% 2$ freference $\% 2$ fannrep_2006_komplett $\% 2$ fsource

\section{United Kingdom}

Currency features:

www.bankofengland.co.uk/banknotes/kyb_lo_res.pdf

www.bankofengland.co.uk/banknotes/security/index.htm

Counterfeit volume:

www.bankofengland.co.uk/publications/annualreport/2005report.pdf www.bankofengland.co.uk/publications/annualreport/2006report.pdf

March 2007 issue of Currency News: Sterling and the Bank of England-A Study in Contradictions

Notes in circulation:

www.bankofengland.co.uk/banknotes/noteissue.pdf

\section{United States}

Currency features: www.moneyfactory.gov/section.cfm/4www.moneyfactory.gov/newmoney/

Counterfeit volume: www.treas.gov/offices/domestic-finance/acd/

Notes in circulation: www.moneyfactory.gov/document.cfm/18/106 